\title{
The Effect of Social Security, Health, Demography and Technology on Retirement*
}

\author{
Pedro Cavalcanti Ferreira ${ }^{\dagger} \quad$ Marcelo Rodrigues dos Santos
}

\begin{abstract}
This article investigates the causes in the reduction of labor force participation of the old. We argue that the changes in social security policy and in technology, and the introduction of Medicare may account for most of the changes in retirement over the second part of the last century in the U.S. economy. We develop a dynamic general equilibrium model with endogenous retirement that embeds social security legislation and Medicare. The model is able to match very closely the increase in the retirement rate of American males and also to reproduce many stylized facts, such as retirement rate by age, by health status and income. We find that changes in social security policy - that became much more generous - account for a sizeable part of the expansion aggregate retirement rate ( $45 \%$ of the observed increase). They also explain, together with Medicare, most of the variation of the retirement profile by age. We found that wealth shocks can influence retirement behavior, so that the strong run-up in stock market in the nineties may have affected the decision of older workers to leave the labor force.
\end{abstract}

Key words: labor supply; aging population; social security; technology change.

JEL classification: D1; D5; J2

\footnotetext{
${ }^{*}$ We wish to thank Flávio Cunha, Rodrigo Soares, Carlos Eugênio da Costa and Samuel Pessôa and seminar participants at Paris1, Cambridge, USP, IBMEC, IPEA for helpful comments. We are responsible for any remaining errors. The authors acknowledge the financial support of CNPq, Faperj, and CAPES.

${ }^{\dagger}$ Both authors are from the Graduate School of Economics ( EPGE ), Fundação Getulio Vargas, Praia de Botafogo 190, 1125, Rio de Janeiro, RJ, 22253-900, Brazil. Email addresses of the authors are, respectively, ferreira@fgv.br and msantos@fgvmail.br.
} 


\section{Introduction}

One of the most important economic changes that took place in the last century, particularly in the second half, was the reduction of labor force participation by seniors. In 1950, $42 \%$ of men older than 64 years in the United States were working, in contrast to only $17.5 \%$ in 2000. Just four out of every ten 66-year-old males were retired in 1950, but fifty years later almost seven out of ten were out of the labor force. This phenomenon is hardly exclusive of the United States. Blondal and Scarpetta (1998) and Gruber and Wise (1999) provide evidence that the workforce participation of the senior population has declined in many countries of the OECD.

The importance of understanding the factors that may account for this sizeable increase in retirement is that they may be in the root of the fiscal crisis that the U.S. Social Security system is faced with today. In fact, according to the Social Security Trustees 2002 Report, in about 15 years the program will begin to experience permanent annual deficits. As a consequence, it is projected that in 2041 the program will not be able to pay legally scheduled benefits.

Because benefits have increased throughout most of this time period, the Social Security system is an obvious suspect for the reduction in labor supply among the elderly. For a long time, economists have investigated the importance of higher Social Security benefits as an explanation for the changes in retirement using a variety of estimation methods. ${ }^{1}$ Nevertheless, this literature has not come to a consensus. In fact, while, for example, Parsons (1982), Gustman and Steimeier (1986) and Rust and Phelan (1997) have found that Social Security benefits have had strong negative effect on male labor supply, Moffitt (1987), Burtless (1986), Stock and Wise (1990) and Krueger and Pischke (1992) concluded that the large increase in real Social Security benefits over the past four decades had little effect. These results suggest that either there are problems associated with the methods that have been used to investigate this relationship, ${ }^{2}$ or there are other explanations that must be taken into consideration. ${ }^{3}$

\footnotetext{
${ }^{1}$ Surveys of the literature can be found in Diamond and Hausman (1984); Sueyoshi (1989) and Rust and Phelan (1997). A more recent survey can be found in Coile and Gruber (2007).

${ }^{2}$ Coile and Gruber (2007), for example, argue that some of these studies consider social security impacts at a point in time, but not effects that come from the time pattern of social security wealth accruals.

${ }^{3}$ Krueger and Pischke (1992) raise this point, after finding little effect of social security benefits on labor supply.
} 
Another key institutional difference between the two periods is the introduction in 1965 of Medicaid and Medicare. The latter provides health insurance coverage to people who are aged 65 and over, while the former is a means-tested, needs-based, social protection program that covers a wide range of health services for the eligible poor. Medicare is a generous insurance against health shocks of the poor and could induce earlier retirement because of the limited need to accumulate precautionary savings. In contrast, because of eligibility requirement, it encourages the delay of retirement until 65. Rust and Phelan (1997) explain part of the observed peak in retirement at age 65 due to "health insurance constrained" individuals who have no form of retiree health insurance other than Medicare. Medicaid can also affect saving and, perhaps indirectly, retirement behavior ${ }^{4}$.

At the same time that Social Security retirement benefits have increased significantly and Medicare and Medicaid were created, there was a marked change in the demographic composition of the population in the U.S., namely, the aging of the population with the consequent expansion of the ratio of seniors to young people. In addition to obvious concerns about budgetary stability - as Social Security spending as a share of GDP tends to increase - the rise in longevity may play an important role in the decision to leave the labor force. In the one hand, Kalemli-Ozcan and Weil (2006), for instance, show that an exogenous decrease in the probability of death, which allows people to better plan saving for old age, generates longer retirement life. On the other hand, higher life expectancy may induce people to remain in the labor force in order to increase savings for old age ${ }^{5}$.

Longevity may play an even stronger role in the decision to leave the labor force since the relative productivity of old workers has been declining in recent years at a faster pace than it used to. In fact, Heckman, Lochner and Todd (2003) provide evidence that older workers have become less productive relative to younger workers over the second part of the last century. A technological explanation for this is most probable. Graebner (1980) argues that technical change leads to retirement, because old people learn slower, making them obsolete in periods of faster innovation, such as the last twenty or thirty years. Moreover, because it reduces the opportunity cost of retirement and raises retirement benefits through increasing lifetime labor earnings, this change in the age-efficiency profile has an important effect on

\footnotetext{
${ }^{4}$ For instance, Kotlikoff (1989) shows that this program reduced precautionary saving against uncertain medical expenses.

${ }^{5}$ Bloom et al. (2007) finds that the effect of increased longevity on savings depends on the social security system. It has no impact in countries with pay-as-you go systems and high replacement rates.
} 
the decision to leave the labor force, as shown by Ferreira and Pessôa (2007).

This article develops and calibrates a stochastic overlapping generational model of large scale in order to investigate the determinants of retirement and the causes of the observed change in the retirement behavior of the American population between 1950 and 2000. We focus on the role of social security, health status, demographic factors (associated with higher longevity), and changes in the experience profile. In the model, individuals decide at each period whether to stay in the labor force or to retire, by comparing the expected return of each option. If they continue working, they also decide how to divide their time between leisure and labor. The usual consumption/saving decision also applies over all periods of the life cycle and if, in poor health, individuals have out-of-pocket expenses with medication. In our model, Medicare decreases the cost of these expenditures for individuals aged 65 or over. Finally, government taxes individuals to finance Social Security pensions and transfer payments. The latter are such that they guarantee a minimum standard of living after medical expenses are paid. These expenditures are financed by taxes on labor and capital incomes, by consumption taxes and Social Security contributions.

The model is calibrated to the U.S. economy in 2000, our benchmark year, and it embeds the rules governing the contributions and payment of Social Security old age benefits and Medicare. The model is able to reproduce very closely the retirement behavior of the American population in the benchmark year. In particular, it reproduces the peaks in the distribution of Social Security applications at ages 62 and 65 and the observed facts that unhealthy and poor individuals retire earlier. Moreover, the model is also consistent with the empirical evidence that unhealthy individuals work fewer hours (French, 2005).

The model is then simulated considering the changes in Social Security, Medicare, ageefficiency profile and demography between 1950 and $2000^{6}$. We find that the simulated labor force participation of older individuals decreases to levels similar to those in the data. We show that the incentives implied by the institutional factors concerning Social Security and Medicare legislation are very effective in influencing retirement behavior. For instance, a contrafactual experiment, in which all parameters were kept at their 2000 values, but the rules of Social Security are changed to those of 1950, finds that for every age group the retirement rate is smaller. More importantly, the peak of retirement at age 62 disappears, as

\footnotetext{
${ }^{6}$ Note that our analysis is a comparison between steady states, one calibrated to 2000 and the other to 1950.
} 
in 1950 there was no early retirement rule. The model is also consistent with the empirical evidence that older workers are working fewer hours (McGrattan and Rogerson, 1998).

An important result is that unexpected wealth shocks, such as the strong run-up in the stock market during the Nineties, may increase leisure in the form of earlier retirement. This is an indication that the markedly different behavior of financial markets in the years prior to 1950 or 2000 may have influenced the decision of older workers to leave the labor force in these two periods, and can potentially explain part of the observed increase in retirement, as Coronando and Perozek (2003) have found.

The present model is related to Rios-Rull (1996), Imrohoroglu, Imrohoroglu and Jones (1995), Huggett and Ventura (1999), Nishiyama and Smetters (2007), and Rojas and Urrutia (2008). These models provide a framework rich enough to deal with all the factors that potentially affect the retirement decision. Besides, this structure allows us to model more accurately the dynamic structure of a social security system. In these papers, however, the retirement decision is exogenous.

Conde-Ruiz and Galasso (2003) endogenize retirement, but in a purely theoretical politicaleconomy framework with no quantitative analysis. French (2005) estimates a partial equilibrium life-cycle model of retirement behavior in which health and wages are uncertain. He uses the model to simulate the impact on the labor supply of modifications to Social Security legislation. Apart from the fact that we work in a general equilibrium model (that is calibrated and not estimated), another relevant difference between the two articles is our focus on the determinants of the evolution of retirement between 1950 and 2000. Finally, Diaz-Gimenez and Diaz-Savavedra (2009) uses an overlapping generational model with an endogenous retirement decision to study pension system reform in Spain. There are many features in their model in common with ours; but as we study the American economy, the calibration and institutional details of the model are obviously very different and so are the experiments we $\mathrm{run}^{7}$.

By endogenizing the retirement behavior, our framework is also very convenient to study the impact of the aging population on the budgetary stability. On the one hand, higher longevity tends to expand the proportion of retirees and so the amount of benefits paid.

\footnotetext{
${ }^{7}$ Another reference is Eisensee (2005) which uses a similar method to study how changes in the Social Security system in the U.S. affected retirement. His model, however, does not allow for idiosyncratic shocks - an important feature of our model - nor health status, which we found to be important to the decision to leave the labor force.
} 
This effect of longevity arises through displacement of individuals toward states in which they are prone to retire. On the other hand, individuals, by living longer, give more weight to the future, which tends to raise capital accumulation, hours worked, and, as a result, the output of the economy. ${ }^{8}$ Hence, it is not clear a priori what the net effect would be. We show that the aging of the population tends to put only a little pressure on the equilibrium of Social Security system finances.

The paper also finds that, even if Social Security benefits had not been changed, total retirement would still be considerably higher today than in 1950, especially because of demographic changes. However, the increase in the Social Security expenses as a share of GDP would be significantly smaller than that observed in data. In contrast, another group of simulations shows that the changes in Social Security account for the greatest part of the increase in the benefits paid-output ratio. In fact, as it will turn out, rising Social Security benefits not only raise the number of retirees, but also undermine the revenue base of the system $^{9}$.

The article is organized as follows. Some retirement facts are presented in Section 2. The model is presented in Section 3 and the calibration procedures and data in Section 4 . In Section 5 results are presented and discussed; Section 6 concludes.

\section{Retirement Facts}

Figure 1 below presents the retirement profile for 1950 and 2000, and was constructed from Census data. It displays the increase in retirement observed in the second half of the last century: for every age there are proportionally more individuals out of the labor force in 2000 than in 1950. Note also that in both cases labor force participation declines after age 55 , before the minimum retirement age according to social security rules in both years (62 and 65 years old, in 1950 and 2000, respectively). In 2000 there were very few people still working at age 75 - less than $10 \%$ - but in 1950 around $25 \%$ of the individuals of that age were still in the labor market.

\footnotetext{
${ }^{8}$ Moreover, the latter effect tends to be amplified if we take into consideration the increase in the productivity of young workers.

${ }^{9}$ The last result is at odds with others in the literature (Krueger and Pischke (1992), for instance) that argue that the reduction of the retirement benefits would have limited impact on the solvency of the system as it has little effect on retirement.
} 
Figure 1: Actual Retirement Rate by Age

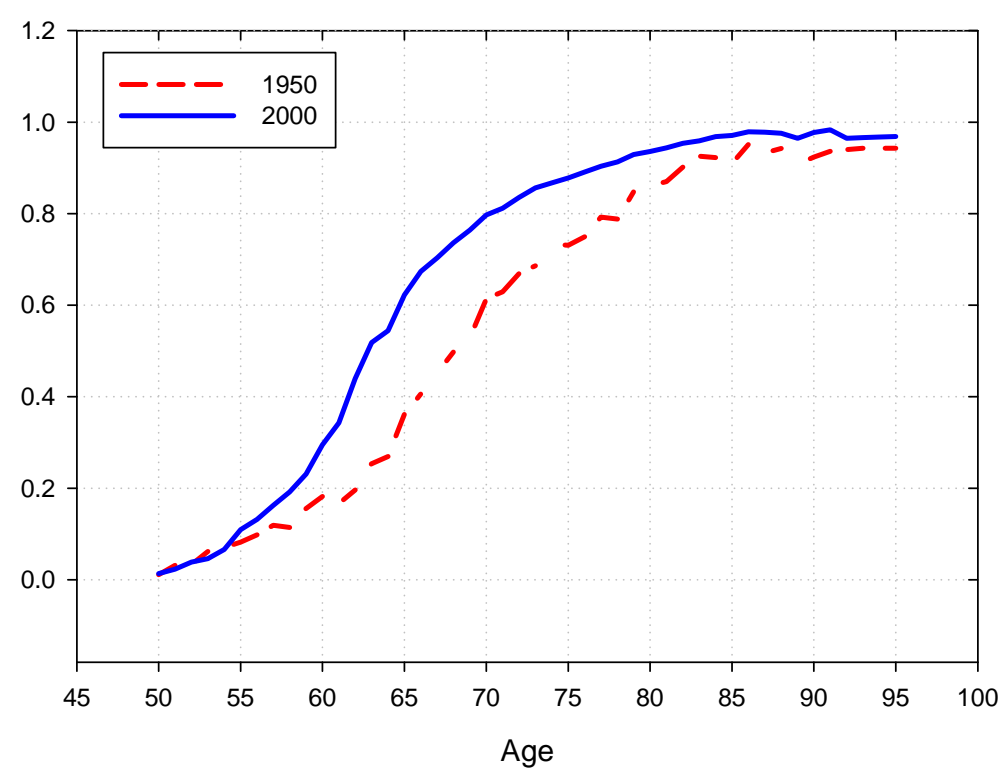

Institutional factors seem to be very important in influencing retirement behavior. The minimum age for eligibility for Social Security benefits is 62, whereas the normal age for retirement benefits (without discount) is 65. The latter is also the age at which eligibility for Medicare starts. There are two peaks in the distribution of retirement at these ages in 2000: fifty-two percent of all applications occur at age 62 , and $18 \%$ at age 65 . The last figure is twice as large as the applications at age 64 .

Poor people retire earlier. According to figures in the table below - constructed using Current Population Survey (CPS) data - in 2000 more than $80 \%$ of the very poor aged 65 to 74 had already left the labor force, but only $23 \%$ of those with personal income between one hundred fifty and two hundred thousand dollars. As a matter of fact, for every age group, labor force participation increases with income. The contrast among the "super-rich" (personal income above 200 thousand dollars) and the very poor is appealing: while almost half of those in the latter group opted for early retirement in 2000 , only $4 \%$ of the former did so. These numbers appear to indicate that income and wealth effects with respect to retirement are not strong. 
Table 1: Individuals Out of the Labor Force by Income (\%) - 2000

\begin{tabular}{cccc}
\hline \hline Personal Income (US\$) & \multicolumn{3}{c}{ Age } \\
\hline \multirow{2}{*}{$0-50000$} & $55-64$ & $65-74$ & $75-84$ \\
\cline { 2 - 4 } $50000-100000$ & 48.1 & 82.5 & 94.4 \\
$100000-150000$ & 14.3 & 48.6 & 75.3 \\
$150000-200000$ & 6.40 & 34.6 & 62.2 \\
200000 or more & 4.00 & 23.1 & 42.2 \\
\hline
\end{tabular}

The retirement behavior with respect to schooling is similar. For a given age group, people with more formal education tend to stay longer in the labor force. Those without a high school degree, for instance, tend to retire before the normal age of retirement. In this case, almost $60 \%$ of the people in this group leave the labor force before age 65 . In contrast, a large majority of college graduates retire after age 64 .

Table 2: Individuals Out of the Labor Force by Schooling (\%) - 2000

\begin{tabular}{cccc}
\hline \hline Schooling & \multicolumn{3}{c}{ Age } \\
\hline & $55-64$ & $65-74$ & $75-84$ \\
\cline { 2 - 4 } Less than High School & 57.4 & 87.5 & 95.9 \\
High School & 42.8 & 81.9 & 93.1 \\
College or more & 27.1 & 69.0 & 88.0 \\
\hline
\end{tabular}

Studies of health status and retirement tend to indicate that those in poor health retire earlier, although there are complications in this case related to the fact that people's health status is not directly observable. For instance, McGarry (2004) finds that poor health has a large effect on labor force attachment: being in fair or poor health is associated with an expected probability of continued work that is 8.2 percentage points lower than for someone in excellent health. This result is consistent with the conclusions of many other studies that used subjective health measures. Dwyer and Mitchell (1999) - which also used more objective measures - found that the influence of health problems on retirement plans is stronger than economic variables. Moreover, men in poor health expected to retire one to two years 
earlier $^{10}$. Rust and Phelan (1997) finds that unhealthy individuals are roughly twice as likely as healthy individuals to apply for social security benefits at the early retirement age. Finally, French (2005) estimates that labor force participation rate of healthy individuals is above that of unhealthy individuals aged 40 and above. He also finds that healthy individuals work more hours.

\section{The model}

\subsection{Demography}

The economy is populated by a continuum of mass one agents who may live at most $T$ periods. There is uncertainty regarding the time of death in every period so that everyone faces a probability $\psi_{t+1}$ of surviving to the age $t+1$ conditional on being alive at age $t$. This lifespan uncertainty entails that a fraction of the population leaves accidental bequests, which, for simplicity, are assumed to be distributed to all surviving individuals in a lumpsum fashion. The age profile of the population, denoted by $\left\{\mu_{t}\right\}_{t=1}^{T}$, is modeled by assuming that the fraction of agents at the age $t$ in the population is given by the following law of motion $\mu_{t}=\frac{\psi_{t}}{\left(1+g_{n}\right)} \mu_{t-1}$ and satisfies $\sum_{t=1}^{T} \mu_{t}=1$, where $g_{n}$ denotes the population growth rate.

Individuals in our economy also face uncertainty pertaining to their health status, which is denoted by a binary variable $h s$ that assumes value 1 if an agent is in good health condition and 0 otherwise. They know $h s$ at the beginning of each period, but future health outcomes are uncertain. Indeed, individuals' health status is assumed to evolve over time according to a first-order Markov process with transition probability matrices $\Pi_{t}=\left[\pi_{t}\left(h s_{t}, h s_{t+1}\right)\right]$, where $\pi_{t}\left(h s_{t}, h s_{t+1}\right)=\operatorname{Pr}\left(h s_{t+1} \mid h s_{t}\right)$.

\subsection{Preferences}

In each period of life, individuals are endowed with one unit of time, which can be split between leisure and work. They maximize the discounted expected utility from consumption, $c_{t}$, and leisure, $l_{t}$, throughout life:

\footnotetext{
${ }^{10}$ Both studies, for methodological reasons, are not subject to "justification bias" (Anderson and Burkhauser (1985)), the fact that estimated health effects using subjective self-assessment of health may be misestimated if individuals use health as an excuse to leave the labor force.
} 


$$
E\left[\sum_{t=1}^{T} \beta^{t-1}\left(\prod_{k=1}^{t} \psi_{k}\right) u\left(c_{t}, 1-l_{t}\right)\right]
$$

where $\beta$ is the intertemporal discount factor and $E$ the expectation operator. The period utility is assumed to take the form of a standard Cobb-Douglas utility function:

$$
u\left(c_{t}, 1-l_{t}\right)=\frac{\left[c_{t}^{\rho}\left(1-l_{t}\right)^{1-\rho}\right]^{1-\gamma}}{1-\gamma}
$$

where $\gamma$ denotes the risk aversion parameter and $1-\rho$ denotes share of leisure in the utility.

We allow for preference heterogeneity in time devoted to work at constant consumption and wage levels. In particular, we follow Kaplan (2007) and assume that $\rho=\frac{1}{1+\xi}$, where $\xi$ follows a log-normal distribution with mean $E_{h s}(\xi)=\bar{\xi}-\varkappa$ hs and variance $\sigma_{\xi}^{2}$. The shock $\xi$ is realized at birth and retained throughout live. This additional source of heterogeneity is intended to take into account variations in work hours that are independent from the variations observed in wages, which may be important for the study of retirement since it allows individuals with similar earnings and history of shocks exhibit different patterns of retirement behavior.

Note that individuals' health status affects preference for leisure. Indeed, it says that, on average, healthy agents (i.e., $h s=1$ ) have stronger preference for work than unhealthy ones (i.e., $h s=0)$. This relationship between the health condition of individuals and the willingness to work is useful to allow the model to replicate the difference in the pattern of hours worked observed in the data between healthy and unhealthy agents.

\subsection{Individuals problem}

\subsubsection{Budget Constraint}

In our model economy, individuals make decisions about labor supply and asset accumulation. Since labor is endogenous, individuals' employment status is defined in terms of how many hours they work. In particular, individuals are considered participating in the labor force at age $t$ if they supply at least $5 \%$ of their time endowment to the labor market and as not working or out of the labor force if they works less than $5 \%$ of their time endowment. ${ }^{11}$

\footnotetext{
${ }^{11}$ Considering one model period as one year, the threshold of $5 \%$ is equivalent to 300 hours a year, assuming an actual time endowment of 6000 hours ( 24 hours a day times 5 days a week times 50 weeks a year). This specification is consistent with others retirement papers in the literature (see, for example, Rust and Phelan,
} 
In addition, as they reach the age of $T_{r}$ and over, they may choose whether or not to apply for retirement benefits. Thus, the age $T_{r}$ is the earliest age at which a worker can start collecting social security benefits in our model.

Individuals' labor productivity is determined by an age-efficiency index denoted by $e\left(z_{t}, \kappa_{t}\right)=$ $\exp \left(z_{t}+\kappa_{t}\right)$, in which $\kappa_{t}$ is a deterministic experience profile for the mean of earnings, and $z_{t}$ is a random component, which evolves according to an $\operatorname{AR}(1)$ process given by $z_{t}=\varphi_{z} z_{t-1}+\varepsilon_{t}$ with innovations $\varepsilon_{t} \sim N\left(0, \sigma_{\varepsilon}^{2}\right)$, and thus accounts for the persistence in lifecycle earnings. Labor productivity shocks are independent across agents and, as a consequence, there is no uncertainty over the aggregate labor endowment even though there is uncertainty at the individual level.

All workers in this economy pay labor income taxes $\left(\tau_{w}, \tau_{s s}\right)$, where the revenue from $\tau_{s s}$ is used to finance the benefit payments to the retirees, and $\tau_{w}$ finances overall government expenditures not related to the social security system. Given that there is a maximum benefit that a retired agent may receive, we consider an upper limit $y_{\max }$ on the taxable income, following the Social Security legislation. Thus, after-tax labor income for an individual who supplies labor $l_{t}$ is given by:

$$
y_{t}=\left(1-\tau_{w}\right) w h_{t} e\left(z_{t}, \kappa_{t}\right)-\tau_{s s} \min \left\{w h_{t} e\left(z_{t}, \kappa_{t}\right), y_{\max }\right\}
$$

Individuals incur medical expenses each period, which are treated as necessary consumption that generates no utility but must be paid. Such expenses amounts to out-of-pocket costs and insurance premia. Following Hubbard et al. (1994) and French and Jones (2007), we model health costs as an exogenous drop in individuals' resources. Empirical evidence in French and Jones (2004) shows that the cost of medical care increases with age and is correlated with individuals' health status. In addition, they find that it exhibits high persistent over time and it is very volatile as well. Based on this evidence, we model healthcare costs as follows:

$$
m e_{t}=q\left(t, h s_{t}, \eta_{t}, u_{t}\right)
$$

where $\left(\eta_{t}, u_{t}\right)$ accounts for the idiosyncratic component of the medical expenses uncertainty, in which $\eta_{t}$ follows an $\mathrm{AR}(1)$ process given by $\eta_{t}=\varphi_{\eta} \eta_{t-1}+\nu_{t}$ with $\nu_{t} \sim N\left(0, \sigma_{\nu}^{2}\right)$ and 1997). 
$u_{t} \sim N\left(0, \sigma_{u}^{2}\right)$ denotes the transitory component. ${ }^{12}$

Individuals can resort to self-insurance to protect themselves against the uncertainty on labor income and medical expenses. Indeed, besides choosing the amount of time to supply to the labor market, they can trade an asset subject to an exogenous lower bound on asset holdings. We assume that this asset, which is denoted by $a_{t}$, takes the form of capital. Thus, savings may be precautionary and allow partial insurance against idiosyncratic shocks. Agents are not allowed to incur debt at any age, so that the amount of assets carried over from age $t$ to $t+1$ is such that $a_{t+1} \geq 0$. Furthermore, given that there is no altruistic bequest motive and death is certain at the age $T+1$, agents who survive until age $T$ consume all their available resources, that is, $a_{T+1}=0$.

We allow individuals that have left the labor force towards retirement to go back to work if they want to do so. Thus, we depart from the standard labor force participation model that treats retirement as an absorbing state. This is consistent with empirical evidence showing that a non-trivial share of retirees, mainly the early ones, end up reentering the labor force following retirement. ${ }^{13}$ The importance of departing from the absorbing state assumption lies in the fact that it may lead the model to understate the expected value of retirement, as some retirees would be better off if they were allowed to go back to work.

As already said, individuals aged $T_{r}$ and over are allowed to apply for social security benefits. Let $b\left(t_{r}, x\right)=q\left(t_{r}\right) b^{n}(x)$ denote these benefits, where $t_{r}$ is the age at which the application takes place, $x$ is the average lifetime earnings, which is calculated by taking into account individual earnings up to age $T_{r}$. We specify the following law of motion for $x$ :

$$
x_{t+1}=\frac{x_{t}(t-1)+\min \left\{y_{t}, y_{\max }\right\}}{t}, t=1, \ldots, T_{r}
$$

The function $b^{n}(x)$ is the benefit that agents are entitled to at full retirement age. It is a piecewise linear function, which is specified in accordance with the rules of the U.S. social security system:

\footnotetext{
${ }^{12}$ MAYBE WE SHOULD MENTION OTHER FACTORS THAT MIGHT AFFECT HEALTHCARE COSTS, BUT ARE NOT BEING CONSIDERED HERE.

${ }^{13}$ Ruhm (1990) shows that about $25 \%$ of workers reenter the labor force following retirement. Nearly $70 \%$ of these movements, which take place mostly before age 65, are into partial retirement, rather than full labor force participation.
} 


$$
b^{n}(x)=\left\{\begin{array}{lr}
\theta_{1} x & \text { if } x \leq y_{1} \\
\theta_{1} y_{1}+\theta_{2}\left(x-y_{1}\right) & \text { if } y_{1}<x \leq y_{2} \\
\theta_{1} y_{1}+\theta_{2}\left(y_{2}-y_{1}\right)+\theta_{3}\left(x-y_{2}\right) & \text { if } \quad y_{2}<x \leq y \max
\end{array}\right.
$$

where $0 \leq \theta_{3}<\theta_{2}<\theta_{1}$ and $\left(y_{1}, y_{2}, y_{3}\right)$ are the bend points of the function.

Thus, up to an average earnings level of $y_{1}$, retirees are entitled to $\theta_{1} x$, so that $\theta_{1}$ corresponds to the retirement replacement rate in this case. If the average past earnings are greater than $y_{1}$ but smaller than $y_{2}$, retirees will earn $\theta_{1} y_{1}+\theta_{2}\left(x-y_{1}\right)$, and finally if the past earnings are greater than $y_{2}$ but below $y$ max, they will receive $\theta_{1} y_{1}+\theta_{2}\left(y_{2}-y_{1}\right)+\theta_{3}\left(x-y_{2}\right)$.

The function $q\left(t_{r}\right)$ captures how the retirement benefits are reduced or increased as individuals start receiving them before or after the normal retirement age, $T_{r}^{n}$. In particular, we have that:

$$
q\left(t_{r}\right)=\left\{\begin{array}{l}
1+g_{e r}\left(t_{r}-T_{r}^{n}\right) \text { if } t_{r} \in\left[T_{r}, T_{r}^{n}\right] \\
\left(1+g_{d c}\right)^{\left(t_{r}-T_{n}\right)} \text { if } t_{r} \in\left(T_{r}^{n}, \bar{T}_{r}\right]
\end{array}\right.
$$

Thus, for each year that agents anticipate their benefits, they will face a linear reduction in their entitlements by a rate of $g_{e r}$. On the contrary, benefits will be increased by a rate of $g_{d c}$ for each year individuals postpone their receipt of social security benefits after reaching the full retirement age, $T_{r}^{n}$. However, this increase no longer applies when them reach age $\bar{T}_{r}>T_{r}^{n}$, even if they continue delaying retirement.

We allow individuals to apply for social security benefits and continue to work, but those that choose to do so may face the retirement earnings test. Considering that the function of the social security benefits is to partially replace lost earnings, the retirement earnings test aims to prevent workers with relatively high earnings from receiving the benefits. The test withholds one dollar in benefits for each $\$ 2$ of annual earnings above an exempt amount for individuals aged $t_{r} \in\left[T_{r}, T_{r}^{n}\right)$ and $\$ 3$ for those aged $t_{r} \in\left(T_{r}^{n}, \bar{T}_{r}\right]$. Formally, the earnings test can be written as follows:

$$
R E T_{t}=\left\{\begin{array}{l}
b_{t}\left(t_{r}, x\right)-\frac{\max \left(y_{t}-y_{r e t, T_{r}}, 0\right)}{2} \text { for } t_{r} \in\left[T_{r}, T_{r}^{n}\right) \\
b_{t}\left(t_{r}, x\right)-\frac{\max \left(y_{t}-y_{r e t, T_{n}}, 0\right)}{3} \text { for } t_{r} \in\left[T_{r}^{n}, \bar{T}_{r}\right]
\end{array}\right.
$$

where $y_{r e t, T_{r}}$ and $y_{r e t, T n}$ are the threshold above which the test applies.

Additionally, in our model economy government provides a minimum consumption, ${ }_{-}$, for 
individuals after medical expenses are paid. We assume that it makes transfers conditional on individuals available resources. In particular, following Hubbard et al. (1994, 1995), we specify:

$$
\operatorname{tra}_{t}=\max \left\{\underline{c}+m e_{t}-\left[1+r\left(1-\tau_{k}\right)\right] a_{t}+y_{t}+\epsilon+R E T_{t} d_{s s, t}, 0\right\}
$$

where $\epsilon$ is the lump-sum transfers due to the accidental bequests and $d_{s s, t}=1$ if the individual has applied for social security benefits, $d_{s s, t}=0$ otherwise.

This equation implies that government transfers fill the gap between an individual's "liquid resources" - which may include not only their wealth and labor income, but also other government transfers such as social security benefits - and the consumption floor. Thus, individuals can always consume at least $c$, even when their disposable resources fall short to cover the out-of-pocket medical expenses. The equation (9) is intended to be a model counterpart for means-tested programs like, for example, Food Stamp and AFDC.

Given all the considerations above, we are in condition now to write down the budget constraint facing an individual in our model economy.

$$
a_{t+1}=\left[1+r\left(1-\tau_{k}\right)\right] a_{t}+y_{t}+\epsilon+t r a_{t}+R E T_{t} d_{s s, t}-m e_{t}-\left(1+\tau_{c}\right) c_{t}
$$

\subsubsection{Recursive formulation of individuals problem}

Let $V_{w, t}\left(s_{t}\right)$ denote the value function of an $t$ year old agent, where $s_{t}=\left(a_{t}, \xi, z_{t}, \eta_{t}, u_{t}, x_{t}, h s_{t}\right) \in$ $S$ is the individual state space, and let $V_{s s, t}^{t_{r}}\left(s_{t}\right)$ for $t=T_{r}, \ldots, T$ denote the value function of an individual aged $t$ that has applied for social security benefits at age $t_{r}$. In addition, considering that agents die for sure at age $T$ and that there is no altruistic link across generations, we have that $V_{T+1}\left(s_{T+1}\right)=0$. Thus, the choice problem of individuals aged $t=1, \ldots, T_{r}-2$ can be recursively represented as follows: ${ }^{14}$

$$
V_{w, t}(s)=\underset{l, a^{\prime} \geq 0}{M a x}:\left[u(c, 1-l)+\beta \psi_{t+1} \sum_{h s^{\prime}} \pi_{t}\left(h s, h s^{\prime}\right) E V_{w, t+1}\left(s^{\prime}\right)\right]
$$

subject to (10) and (5), where $s^{\prime}=\left(a^{\prime}, \xi, z^{\prime}, \eta^{\prime}, u^{\prime}, x^{\prime}, h s^{\prime}\right)$.

While the problem of individuals aged $t=T_{r}-1, \ldots, T$ can be written as:

\footnotetext{
${ }^{14}$ In order to simplify the notation, we have suppressed the subscript for age from both the state and control variables.
} 


$$
V_{w, t}(s)=\underset{l, a^{\prime} \geq 0}{\operatorname{ax}}:\left[u(c, 1-l)+\beta \psi_{t+1} \sum_{h s^{\prime}} \pi_{t}\left(h s, h s^{\prime}\right) E \max \left\{V_{w, t+1}\left(s^{\prime}\right), V_{s s, t+1}^{t+1}\left(s^{\prime}\right)\right\}\right]
$$

where $V_{s s, t}^{t_{r}}(s)$ is given by:

$$
V_{s s, t}^{t_{r}}(s)=\underset{l, a^{\prime} \geq 0}{\operatorname{ax}}:\left[u(c, 1-l)+\beta \psi_{t+1} \sum_{h s^{\prime}} \pi_{t}\left(h s, h s^{\prime}\right) E V_{s s, t+1}^{t_{r}}\left(s^{\prime}\right)\right]
$$

subject to $(10)$, where $s^{\prime}=\left(a^{\prime}, \xi, z^{\prime}, \eta^{\prime}, u^{\prime}, x, h s^{\prime}\right)$.

Solving the dynamic programs in (11) and (12), we obtain decision rules for labor supply $d_{l, t}: S \rightarrow[0,1]$, asset holdings $d_{a, t}: S \rightarrow R_{+}$, consumption $d_{c, t}: S \rightarrow R_{++}$. The policy function pertained to the decision of applying to social security retirement benefits, $d_{s s, t}$ : $S \rightarrow\{0,1\}$, is also obtained by solving (11) and (12). Note, however, that individuals may only apply for them at age $t \geq T_{r}$. Also, once they apply, they are not allowed to forsake the benefits, which means that if $d_{s s, t-1}=1$, then $d_{s s, t}=1$.

\subsection{Government}

In our economy, the government manages a social security system, wherein the pension benefits to pensioners are financed through an exogenous $\operatorname{tax} \tau_{s s}$. The amount of benefit received by each retired agent depends on his or her individual average lifetime earnings through a concave, piecewise linear function, which will be presented below. Additionally, government carries out an exogenous stream of expenditures, $G$, which is financed by proportional taxes on consumption, $\tau_{c}$, labor income, $\tau_{w}$, and capital income, $\tau_{k}$. Moreover, it is assumed that the government does not incur debt, so that we allow $\tau_{c}$ to adjust in order to balance its budget constraint in equilibrium. Finally, we assume that the government collects the accidental bequests and transfers it to all agents in the economy on a lump-sum basis.

\subsection{Technology}

The technology in this economy is given by a Cobb-Douglas production function with constant returns to scale, which is specified by $Y=K^{\alpha} N^{1-\alpha}$ where $\alpha \in(0,1)$ is the output share of capital income, and $Y, K$ and $N$ denote aggregate output, capital and labor respec- 
tively. We assume that this technology is managed by a representative Firm, which behaves competitively in a sense that it picks capital and labor to maximize its profit, taking prices as given. Thus, the problem of the representative Firm can be written as follows:

$$
\Pi=\underset{K, N}{\operatorname{ax}}: K^{\alpha} N^{1-\alpha}-w N-(r+\delta) K
$$

where $\delta$ is the depreciation rate of capital.

Thus, the first-order conditions of Firm's maximization problem are:

$$
\begin{aligned}
r & =\alpha\left(\frac{K}{N}\right)^{\alpha-1}-\delta \\
w & =(1-\alpha)\left(\frac{K}{N}\right)^{\alpha}
\end{aligned}
$$

\subsection{Equilibrium}

At each point of time, agents are heterogeneous in regard to age $t$ and to state $s \in S$. The agents' distribution at age $t$ among the states $s$ is described by a measure of probability $\lambda_{t}$ defined on subsets of the state space $S$. Let $\left(S, \Omega(S), \lambda_{t}\right)$ be a space of probability, where $\Omega(S)$ is the Borel $\sigma$-algebra on $S$. Thus, for each $\omega \subset \Omega(S)$, we have that $\lambda_{t}(\omega)$ denotes the fraction of agents aged $t$ at that are in $\omega$. The transition from age $t$ to age $t+1$ is governed by the transition function $Q_{t}(s, \omega)$, which depends on the decision rules and on the exogenous stochastic process for $(z, \eta, u, h s)$. The function $Q_{t}(s, \omega)$ gives the probability of an agent at age $t$ and state $s$ to transit to the set $\omega$ at age $t+1$.

Definition 1 Given the policy parameters, a recursive competitive equilibrium for this economy is a collection of value functions $\left\{V_{w, t}(s), V_{s s, t}^{t_{r}}(s)\right\}$, policy functions for individual asset holdings $d_{a, t}(s)$, for consumption $d_{c, t}(s)$ and for labor supply $d_{l, t}(s)$, Social Security benefit claiming decisions $d_{s s, t}(s)$, prices $\{w, r\}$, age dependent but time-invariant measures of agents $\lambda_{t}(s)$, transfers $\epsilon$ and a tax on consumption $\tau_{c}$ such that:

1) $\left\{d_{a, t}(s), d_{l, t}(s), d_{c, t}(s), d_{s s, t}(s)\right\}$ solve the dynamic problems (11) and (12);

2) The individual and aggregate behaviors are consistent, that is: 


$$
\begin{aligned}
K & =\sum_{t=1}^{T} \mu_{t} \int_{S} d_{a, t}(s) d \lambda_{t} \\
N & =\sum_{t=1}^{T} \mu_{t} \int_{S} d_{l, t}(s) e\left(z_{t}, \kappa_{t}\right) d \lambda_{t}
\end{aligned}
$$

3) $\{w, r\}$ are such that they satisfy the optimum conditions (14) and (15);

4) The final good market clears:

$$
\sum_{t=1}^{T} \mu_{t} \int_{S}\left\{d_{c, t}(s)+\left[d_{a, t}(s)-(1-\delta) d_{a, t-1}(s)\right]\right\}=K^{\alpha} N^{1-\alpha}
$$

5) Given the decision rules, $\lambda_{t}(\omega)$ satisfies the following law of motion:

$$
\lambda_{t+1}(\omega)=\int_{S} Q_{t}(s, \omega) d \lambda_{t} \quad \forall \omega \subset \Omega(S)
$$

6) The distribution of accidental bequests is given by:

$$
\epsilon=\sum_{t=1}^{T} \mu_{t} \int_{S}\left(1-\psi_{t+1}\right) d_{a, t}(s) d \lambda_{t}
$$

7) $\tau_{c}$ is such that it balances the government's budget:

$$
\frac{G+S S B+\sum_{t=1}^{T} \mu_{t} \int_{S} \operatorname{tra} a_{t}(s) d \lambda_{t}-\tau_{k} r K-\tau_{w} w N}{C}
$$

where $S S B$ is the social security balance and $C$ denotes the aggregate consumption. 


\section{Data and calibration}

In this section, we describe the data used to calculate the model and the calibration procedures $^{15}$. Initially, the model is calibrated taking into account 2000 data, which is set as a benchmark. Afterwards, we introduce into the model the changes observed in the economic environment between 1950 and 2000 and investigate whether or not our model can replicate some stylized facts regarding to retirement behavior. Finally, we isolate the effect of the social security, of aging population, of Medicare and of the individual productivity profile and investigate the relative importance of each of these factors to the changes in retirement behavior in the period.

\subsection{Demography}

The population age profile $\left\{\mu_{t}\right\}_{t=1}^{T}$ depends on the population growth rate $g_{n}$, on the survival probabilities $\psi_{t}$ and on the maximum age $T$ that an agent can live. In this economy, a period corresponds to one year and an agent can live 81 years, so that $T=81$. Additionally, we assumed that an individual is born with 20 years old, so that the real maximum age is 100 years old.

Given the survival probabilities, the population growth rate in 1950 and in 2000 is chosen so that the age distribution in the model replicates the dependency ratio observed in the data. Thus, we set $g_{n}=0.0125$ for 1950 and $g_{n}=0.0105$ for 2000 . These values generate dependency ratios of $12.13 \%$ and $17.27 \%$, respectively. By modeling the age-population distribution in the model in such a way that it replicates the dependency ratio on data, we are able to capture the large increase in the number of individuals eligible for social security retirement benefits over the period under study. ${ }^{16}$

Data on survival probability by age and by health status were extracted from Bell and Miller (2005) and French (2005). As Figure 2 suggests, life expectancy has increased from 1950 to 2000, as the survival probability profile shifted up and to the right in the period. For example, conditional on being alive at age 20, expected life span was 69 years old in 1950 for an individual in good health condition, while this same agent was expected to live nearly 75

\footnotetext{
${ }^{15}$ The standard calibration procedure of overlapping generations models can be found in Auerbach and Kotlikoff (1987) and in Rios-Rull (1996), which we follow here.

${ }^{16}$ The number of individuals eligible for social security benefits has also increased because of amendments to the social security regulations. For example, in 1954 were added agricultural workers, farm and domestic workers. For simplicity, in this paper we focus on the changes in the age-population distribution.
} 
years in 2000. Likewise, the longevity of a healthy individual aged 50 rose from 72 to about 78 years during the same period.

Figure 2: Survival Probability by Age and Healthy Status

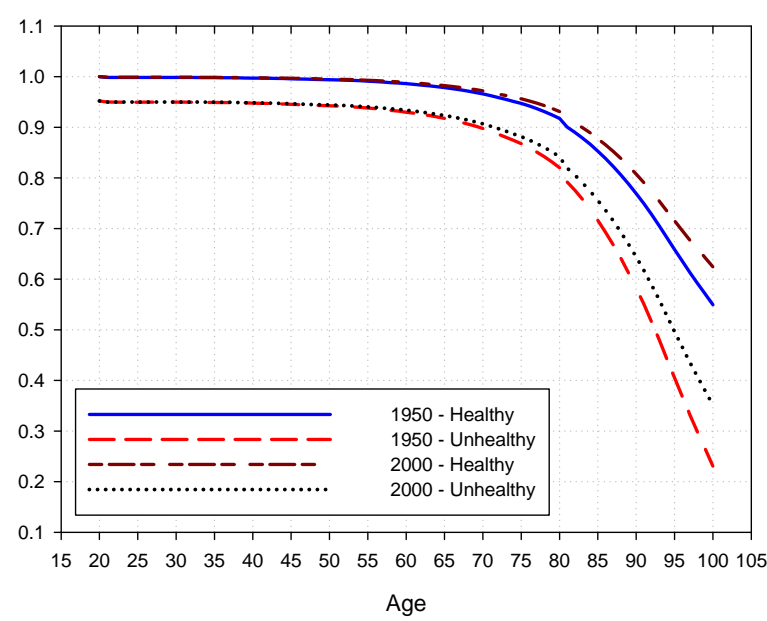

Figure 3: Probability of Having Good Health in $t+1$

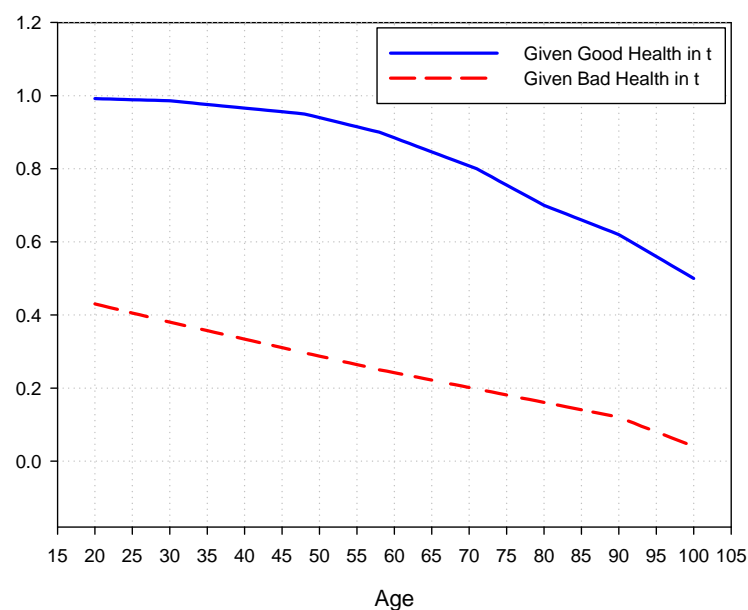

The transition probability matrices $\Pi_{t}=\left[\pi_{t}\left(h s_{t}, h s_{t+1}\right)\right]$ were constructed using estimates from French (2005) for the probability of having good health in $t+1$ conditional on the health status in $t$. Figure 3 shows such probabilities for both cases: poor and good health in period $t$. As one should expect, the probability of being healthy tomorrow decreases with age and is far higher for healthy agents than for individuals with poor health today, which suggests high persistence of health shocks over the life-cycle.

\subsection{Preferences and technology}

The values of the parameters related with the individual preferences $\left(\beta, \gamma, \bar{\xi}, \sigma_{\xi}^{2}, \varkappa\right)$ are summarized in Table 1 . The intertemporal discount rate, $\beta$, was chosen to match a capital-output ratio of 3 . On a yearly basis, it turned out to be 1.0 in the benchmark economy. The parameters of the stochastic process of shocks on the preference for leisure $\left(\bar{\xi}, \sigma_{\xi}^{2}\right)$ are from Kaplan (2007) and we set $\gamma=3$. For Cobb-Douglas preferences, the coefficient of relative risk aversion is given by $1-\rho+\rho \gamma$ and the Frisch elasticity for leisure is given by $\frac{1-\rho+\rho \gamma}{\gamma}$. For an individual with $\xi=\bar{\xi}$, the values reported in Table 1 entail a value of 1.62 for the coefficient of relative risk aversion and of 0.54 for the Frisch Elasticity for leisure. These 
values are consistent with the empirical evidence in Auerbach and Kotlikoff (1987), Rust and Phelan (1997) and Domeij and Flodén (2006).

In representative agent models, given the capital income share and the depreciation rate, there is a one to one relationship between the parameter $\rho$ and the fraction of time that individuals spend working in the stationary state. In overlapping generation models with heterogenous agents, however, such relation is more complicated. In this case, the usual procedure used to choose $\rho$ is such that the average fraction of time that individuals spend working is consistent with the empirical evidence, which suggests a value around $30 \% .{ }^{17}$ In our model economy, since $\rho=\frac{1}{1+\xi}$, average hours worked is governed by $\bar{\xi}$ and, given a value of 2.21 for $\bar{\xi}$, individuals devote $28.6 \%$ of their time to the labor market under the baseline calibration.

Table 3: Preferences and Technological Parameters

\begin{tabular}{cccccccc}
\hline \hline$\beta$ & $\gamma$ & $\bar{\xi}$ & $\sigma_{\xi}^{2}$ & $\varkappa$ & $\alpha$ & $\delta$ & $c$ \\
1.0 & 3.0 & 2.21 & 0.25 & 0.20 & 0.36 & 0.06 & 0.05 \\
\hline
\end{tabular}

The parameter $\varkappa$ is calibrated in order for the model to replicate the difference in the pattern of hours worked between healthy and unhealthy individuals over the life-cycle. French (2005) shows that at any point in the life cycle, the effect of health on working hours is sizeable, ranging from 10 to 20 percent. By using a value for $\varkappa$ of 0.20 , the model yields that poor health individuals work, on average, $13 \%$ less than what the good health ones do. Figure 4 shows the average hours worked among healthy and unhealthy agents for the benchmark case.

\footnotetext{
${ }^{17}$ See, for instance, Juster and Stafford (1991).
} 
Figure 4: Average Hours Worked by Health Status

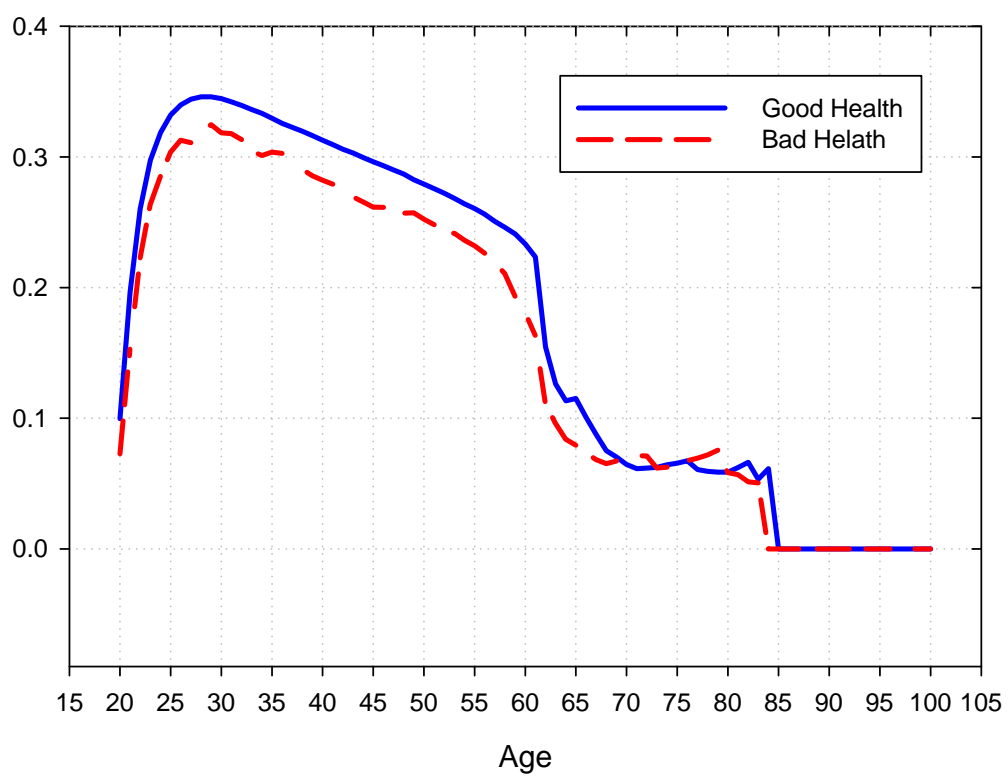

The value for the consumption floor, ${ }_{-}$, reported in Table 1 is set to be $15 \%$ of the average income of the benchmark economy, which is consistent with the empirical evidence. Indeed, using means-tested transfer payments such as AFDC, Food Stamps, section 8 housing assistance and SSI, Hubbard et al. (1995) estimate a valor of $\$ 7000$ for $\underline{c}$, which in 2000 dollars corresponded to nearly $18 \%$ of the average income in the US economy. Using a similar procedure, French and Jones (2007) find a value of $\$ 4000$, which is nearly $10 \%$ of the average income in 2000.

The values of technological parameters $(\alpha, \delta)$ are also summarized in Table 1 . We chose a value for $\alpha$ based on U.S. time series data from the National Income and Product Accounts (NIPA). The depreciation rate, in turn, is obtained as $\delta=\frac{I / Y}{K / Y}-g$. We set the investmentproduct ratio $I / Y$ equal to 0.25 and the capital-product ratio $K / Y$ equal to 3.0. The economic growth rate, $g$, is constant and consistent with the average growth rate of GDP over the second half of the last century. Based on data from Penn-World Table, we set $g$ equal to $2.7 \%$, which yields the depreciation rate reported in Table 1. 


\subsection{Individual labor productivity}

Each agent in this economy is endowed with an individual productivity level $e\left(z_{t}, \kappa_{t}\right)$. Following Huggett and Ventura (1999) and Huggett and Parra (2010), we specify $e\left(z_{t}, \kappa_{t}\right)=$ $\exp \left(z_{t}+\kappa_{t}\right)$, where $\kappa_{t}$ denotes the age-efficiency profile and $z_{t}$ denotes the persistent shocks on earnings, with the underline stochastic process being characterized by the parameters $\left(\varphi_{z}, \sigma_{\varepsilon}^{2}\right)$. Several authors have estimated similar stochastic processes for labor productivity. ${ }^{18}$ Controlling for the presence of measurement errors and/or effects of some observable characteristics as education and age, the literature provides a range of $[0.88,0.96]$ for $\pi$ and of $[0.10,0.25]$ for $\sigma_{\varepsilon}$. In this article, we follow the estimates of Flodén and Lindé (2001) and set $\varphi_{z}$ and $\sigma_{\varepsilon}^{2}$ to be equal to 0.91 and 0.016 , respectively.

The values for $\kappa_{t}$ are constructed similarly to Huggett (1996) and MacGrattan and Rogerson (2007). We use annual earnings and annual hours worked for the age groups 15-24, 25-34,..., 75-84 from Integrated Public Use Microdata Series (IPUMS) (U.S. Department of Commerce, Bureau of the Census 1950-2005). First, we construct hourly wages dividing annual earnings by annual hours for age group. Afterwards, we use a second order polynomial to interpolate the points in order to obtain the age-efficiency profile by exact age. We then truncate the polinomial to zero when it goes below zero which happens at age 91 for 2000 and 92 for 1950. Figure 5 shows the profiles for 1950 and 2000 that are utilized in our calculations. The profiles shown in the figure are consistent with the empirical evidence provided by Heckman et. al. (2003) who show that the efficient indexes for older workers are smaller in 1990 than in $1950 .^{19}$

\footnotetext{
${ }^{18}$ A revision of this literature can be found in Atkinson et. al. (1992).

${ }^{19}$ See also Ferreira and Pessoa (2007). We have not used the age-efficiency profiles estimated by Heckman et. al. (2003) because they do not provide estimates for 2000.
} 
Figure 5: Age-Efficiency Profile

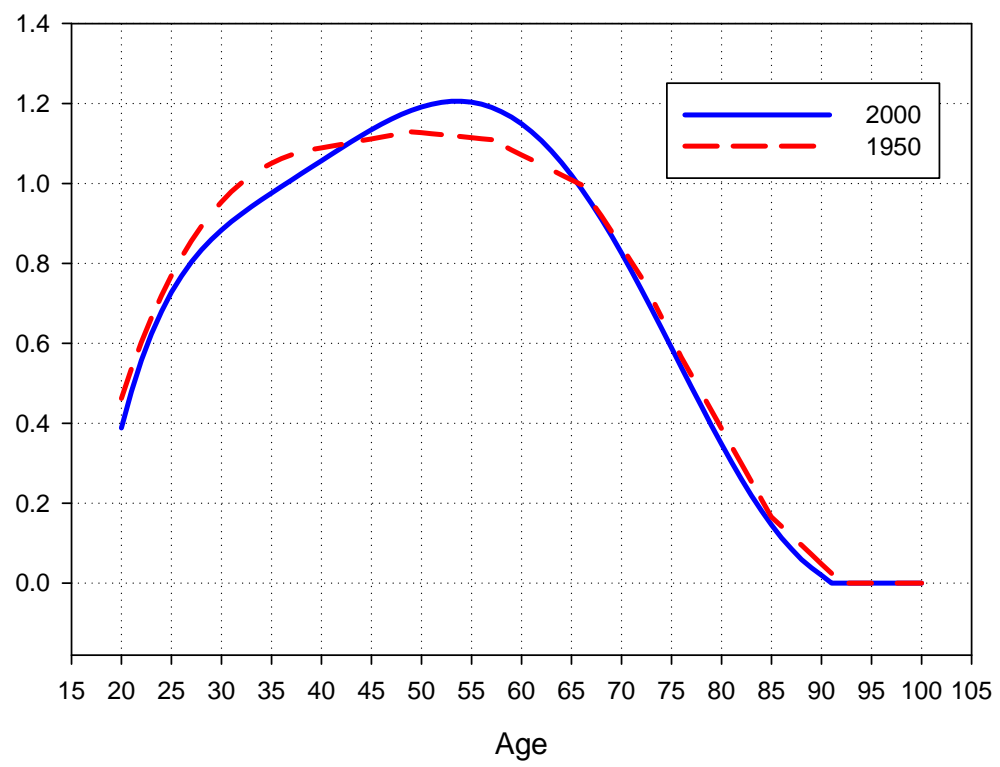

This fall in the relative productivity of older workers can be explained by technological progress. As shown in Sala-i-Martin (1996), changes in the technology of production have lowered the productivity of older workers thereby leading employers to replace them. Similarly, Graebner(1980) maintains that technological change leads to retirement because the learning of old people is slower, making then obsolete in periods of faster innovation. ${ }^{20}$

\subsection{Medical expenses and Medicare}

The out of pocket medical expenses function, $q\left(t, h s_{t}, \eta_{t}, u_{t}\right)$, is parameterized as follows:

$$
q\left(t, h s_{t}, \eta_{t}, u_{t}\right)=\chi_{t} \exp \left(\eta_{t}+u_{t}\right)\left(1-\varrho h s_{t}\right)
$$

where $\chi_{t}$ captures the effect of age on healthcare costs.

The parameters $\left(\varphi_{z}, \sigma_{\nu}^{2}, \sigma_{u}^{2}\right)$ that characterize the idiosyncratic component of the medical expenses uncertainty, along with the parameter $\varrho$, which captures the effect of health status on out of pocket expenses, are taken from French and Jones (2004). Table 4 reports the values of these parameters. As one can see in the Table, the estimates in French and Jones

\footnotetext{
${ }^{20}$ Blondal and Scarpetta (1999) also argue that the labor market for elderly has worsened because of technology changes.
} 
reveal that not only are the shocks on medical expenses very persistent, but also they are very volatile, with nearly $50 \%$ of the cross-sectional variace in spending being generated by transitory shocks.

Table 4: Parameters

\begin{tabular}{cccc}
\hline \hline$\varphi_{z}$ & $\sigma_{\nu}^{2}$ & $\sigma_{u}^{2}$ & $\varrho$ \\
\hline 0.922 & 0.05 & 0.50 & 0.28 \\
\hline
\end{tabular}

We construct the age-medical expenditures plofile, $\chi_{t}$, for the benchmark economy using the estimates of per person healthcare costs by age reported in Meara et al. (2004). Based on data from five national household surveys: the 1963 and 1970 Surveys ofHealth Services Utilization and Expenditures; National Medical Care Utilization and Expenditure Survey; the National Medical Expenditure Survey; and the Medical Expenditure Panel Survey, they estimate per person spending for 2000 and for the following age groups: 5-14,15-24, 25$34, \ldots, 75+$. We use a second order polynomial equation to interpolate these points in order to obtain the age profile by exact age. The interpolated profile is displayed in Figure 6 . Finally, we normalize the profile dividing it by the average annual wage, which, according to the Social Security Bulletin (2001), was $\$ 36564$.

Figure 6: Medical expenses by Age (US\$) - 2000

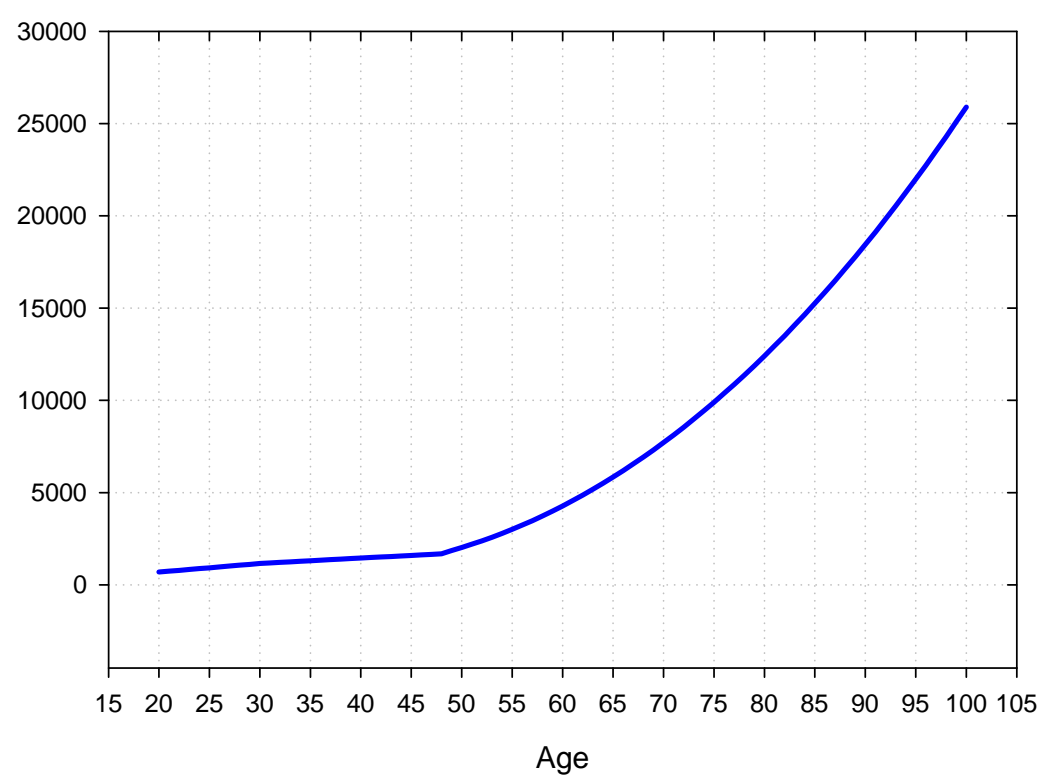

Finally, we study the effect of Medicare on retirement by investigating how it has changed 
the out of pocket medical spending function (16). Finkelstein and McKnight (2008) identify the effect of Medicare on healthcare expenditures comparing changes in spending for individuals over age 65 to changes in spending for individuals under age 65 between 1963 and 1970. To increase the plausibility of the identifying assumption that, absent Medicare, changes in various types of spending for individuals above and below age 65 would have been the same, they focus primarily on changes in spending for the "young elderly" (ages 65 to 74) relative to that for the "near elderly" (ages 55 to 64). The authors find that the introduction of Medicare is associated with a decline in mean out of pocket spending of $\$ 117$, which represents a one-quater decline from the out of pocket expenditures by the young elderly in 1963. In our context, it means that without Medicare, the out of pocket spending function (16) is shifted up by $25 \%$ for individuals aged 65 and over.

\subsection{Social Security and Taxation}

The social security system in our economy is modeled so that it takes into consideration the main characteristics of the U.S. Social Security System. In 1950, the earliest age at which a person could receive Social Security retirement benefits was 65 so we set $T_{r}$ equal to 46 in the benchmark economy. After 1961, however, age 62 was adopted as an early retirement age, with reduced benefits. In our context, this implies that $T_{r}=43$ for 2000 . The normal retirement age is the age at which a person may first become entitled to unreduced retirement benefits. This age was 65 in 1950 and in 2000, so we have that $T_{r}^{n}=46$ for both years. ${ }^{21}$

In the United States the old-age benefit payable to the worker upon retirement at full retirement age is called the primary insurance amount (PIA). The PIA is derived from the worker's annual taxable earnings, averaged over a period that encompasses most of the worker's adult years. Until the late 1970s, the average monthly wage (AMW) was the earnings measure generally used. For workers first eligible for benefits after 1978, average indexed monthly earnings (AIME) have replaced the AMW as the usually applicable earnings measure. In our context, both AMW and AIME are given by (5).

The complete parameterization of the benefits function requires the specification of values for the parameters $\left\{\theta_{1}, \theta_{2}, \theta_{3}, y_{1}, y_{2}, y \max \right\}$. The values used for each one of those parameters are presented in Table 5 . The parameters $\left(y_{1}, y_{2}\right)$ correspond to the bend points applied in the

\footnotetext{
${ }^{21}$ The normal retirement age will increase gradually to 67 for persons reaching that age in 2027 or later, beginning with an increase to 65 years and 2 months for persons reaching age 65 in 2003.
} 
formula of calculation of the PIA, while $\left(\theta_{1}, \theta_{2}, \theta_{3}\right)$ determine the replacement rate applied in each one of the intervals defined by the bend points. For 1950 we used the bend points applied to calculate the PIA from creditable earnings after 1936 according to the Social Security Bulletin (2001). In this case, the PIA corresponds to $40 \%$ of first $\$ 50$ of AMW plus $10 \%$ of next $\$ 200$ of AMW. We multiplied these values by 12 , adapting to the annual base of the model and then we normalized the result by dividing by the average annual wage.

\begin{tabular}{ccccccc}
\hline \hline \multicolumn{7}{c}{ Table 5: Benefit Function Parameters } \\
\hline \hline \multirow{2}{*}{1950} & $y_{1}$ & $y_{2}$ & $y_{\max }$ & $\theta_{1}$ & $\theta_{2}$ & $\theta_{3}$ \\
\cline { 2 - 8 } 2000 & 0.23 & - & 1.13 & 0.40 & - & 0.10 \\
\hline
\end{tabular}

We followed similar procedure for 2000. The values in this case correspond to those applied in the calculation of the PIA for workers who were first eligible in 1979 or later according to Social Security Bulletin (2001). In 2000, the PIA equalled $90 \%$ of first $\$ 531$ of AIME, $32 \%$ of next $\$ 2671$ and $15 \%$ of AIME over 3202 . We, again, divide these values by the average annual wage. ${ }^{22}$

If individuals retire between 62 and 65 years old, their benefits are reduced by a formula that takes into account the remaining time to reach the normal retirement age. Thus, according to the Social Security Supplement (2001), if individuals retire at age 62, 63 or 64 they will receive $80 \%, 86.7 \%$ and $93.3 \%$ of the full retirement benefit, respectively. Thus we set $g_{e r}=0.067$. On the other hand, social security benefits are increased by a given percentage if individuals delay their retirement beyond the normal retirement age. This delayed retirement credit was instituted in 1972 to provide a bonus to compensate for each year past age 65 that a person delays receiving benefits, until age 70 . Hence, $g_{d c}$ is equal to zero in our economy in 1950 . For 2000 , we set $g_{d}$ equal to 0.04 , which is the delayed retirement credit for those born in 1929-1930.

Figures $7 \mathrm{a}$ and $7 \mathrm{~b}$ plot the benefit function obtained for 1950 and for 2000, respectively. The horizontal axis corresponds to the average past earnings $x$ and the vertical axis corresponds to the benefit. We have normalized both figures so that the average earnings in the economy, ym, is set equal to one. Thus, for example, if an individual has $x$ exactly equal to

\footnotetext{
${ }^{22}$ According to the Social Security Bulletin (2001), the average annual wage in 2000 was $\$ 36564$ and in 1950 was $\$ 2654$.
} 
$y m$, his benefit would be equal to $17 \%$ of the corresponding value in 1950 . In contrast, his benefit would be $42 \%$ of $y m$ in 2000 . Hence, it is immediate to see from Figures $3 \mathrm{a}$ and $3 \mathrm{~b}$ that benefits have become much more generous between 1950 and 2000.

Remember that $y$ max corresponds to the level of earnings above which earnings in Social Security covered employment is neither taxable nor creditable for benefit computation purposes. In 1950, the maximum taxable annual earning was $\$ 3000$, while in 2000 it was $\$ 76200$. We, then, divided these values by the average annual wage for both years in order to obtain ymax $=\{1.13,2.34\}$, respectively.

Figure 7a: Benefit Function - 1950

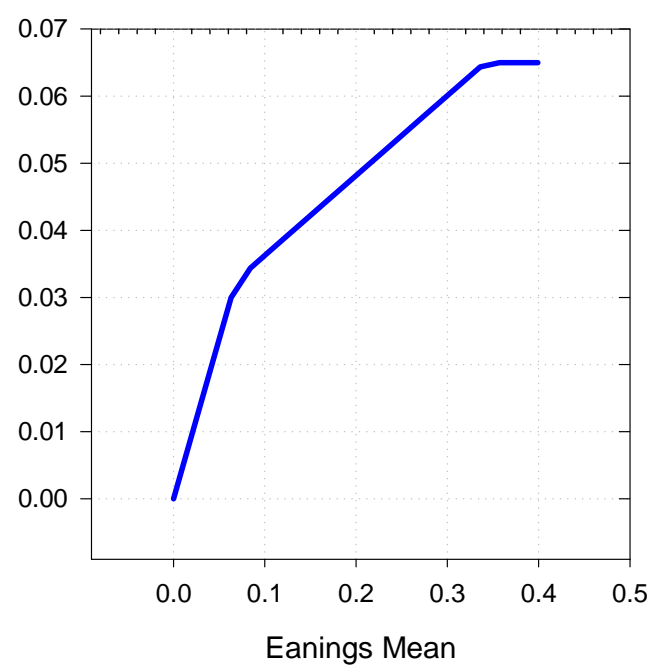

Figure 7b: Benefit Function - 2000

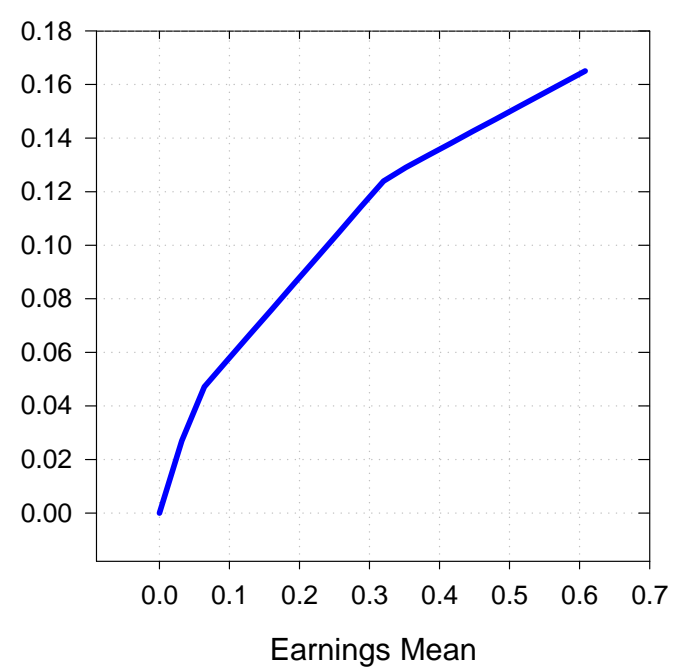

Remember also that the parameter $\tau_{s s}$ denotes the contribution from workers to the social security system. In 1950, American workers covered by the social security system contributed with $3.0 \%$ of their wages for Old-Age and Survivors Insurance (OASI), which pays monthly cash benefits to retired worker (old-age) beneficiaries, while in 2000 that contribution was 10.6\%. Thus, we set $\tau_{s s}=0.03$ for 1950 and $\tau_{s s}=0.106$ for $2000 .^{23}$

The amount exemption of the retirement earnings test for individuals aged 62-64 was $\$ 10080$ in 2000 , while it was $\$ 17000$ for individuals aged $65-70$. These values correspond, respectively, to $27 \%$ and $46 \%$ of the average wages economy in 2000 . Thus, we set $y_{r e t, T_{r}}$ and $y_{r e t, T n}$ to be $0.27 y_{m}$ and $0.46 y_{m}$, where $y_{m}$ is the average labor income in the benchmark

\footnotetext{
${ }^{23}$ These values come from the Social Security Bulletin (2001) and are the combined employee-employer $\operatorname{tax}$ for (OASI).
} 
economy. There is not RET for the 1950 economy.

Finally, we specify the others parameters related to the government activity. First we set government consumption $G$ to be $18 \%$ of the output of the economy. We assume a labor income tax rate of $14 \%$ and a capital income tax rate of $27 \%$. The consumption tax is set such that the government budget balances, which implies a tax rate equal to $8.4 \%$ at the benchmark economy. These values are consistent with others retirement papers that also take into account a model general tax system (see, for example, Fuster el at., 2007 and 2008).

\section{Results}

The retirement rate by age in the model, $\lambda_{t}$, is given by the measure of agents at age $t$ that are out of the labor force $\lambda_{t}$. Figure 8 presents the retirement rate generated by the model for the benchmark case and the retirement profile observed in the U.S. economy in 2000. In the last case, data on the status of labor force from the Census were used. For each age, we have divided the fraction of people who are out of the labor force by the fraction of those who are in the labor force, leaving aside those who never participated in the labor force. ${ }^{24}$

Figure 8: Individuals Out of the Labor Force - 2000

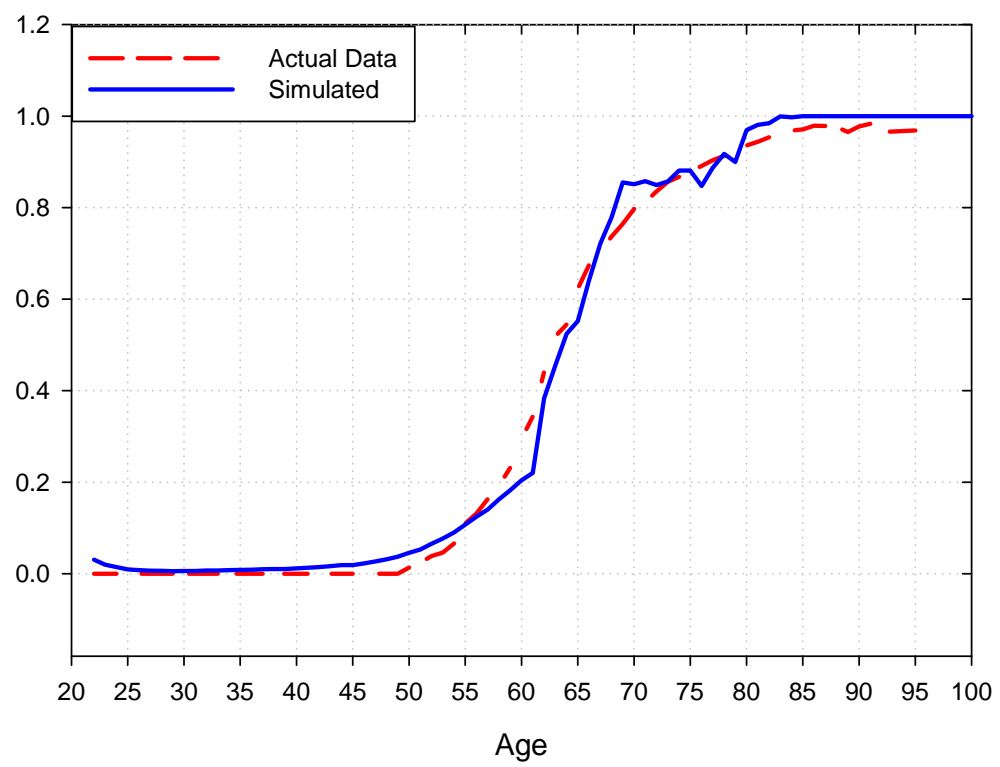

The model is able to reproduce very closely the retirement profile by age in 2000 . In

\footnotetext{
${ }^{24}$ This calculation is similar to that used in Kopecky (2006).
} 
particular, it captures the jump in retirement at ages 62 and 65 and the relative large the number of individuals out of the labor force before they reach the minimum eligible age for early retirement. Note that, in the data and in the simulation, almost $15 \%$ of the 55 -year-old individuals were out of the labor force in 2000. The figures below present the retirement profile for the upper and lower quintiles of average past earnings (" $x^{\prime \prime)}$, on the left, and retirement profile by health status on the right:

Figure 9: Individuals Out of the Labor Force by Average Past Earnings - 2000

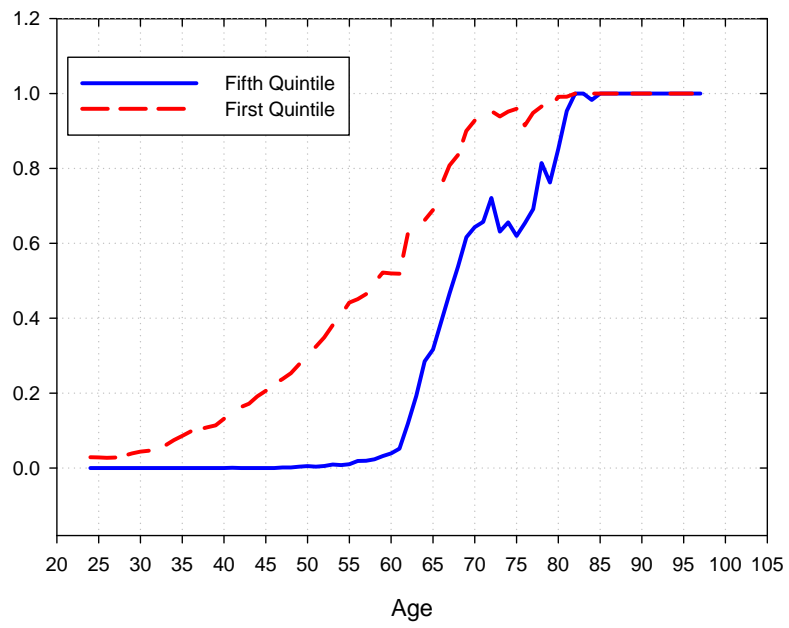

Figure 10: Individuals Out of the Labor Force by Health Status - 2000

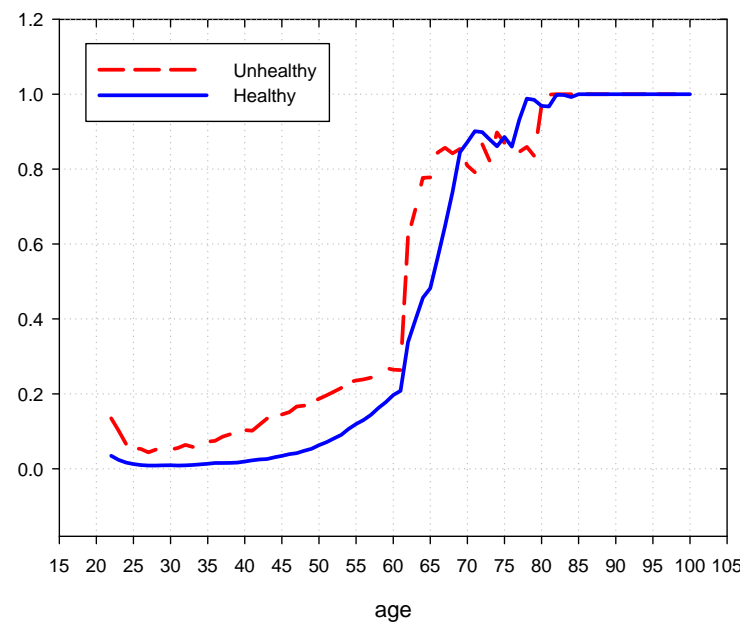

Rich people tend to retire later than poor people. Phelan and Rust (1997) estimates that individuals with low incomes and low average wages are nearly three times as likely to choose to quit working; whereas, individuals with the highest incomes are more likely to continue working full-time. The model reproduces these facts. For every age group, the retirement rate of poor individuals is above that of the rich. According to the simulations, at age 70, less than $65 \%$ of the individuals in the fifth quintile of past income are out of the labor force. In contrast, at the same age, around $90 \%$ of the bottom quintile left the labor force. Moreover, in the case of the top quintile, less than $40 \%$ of individuals retire at or before the normal age. (an indication that the delayed retirement credit is operative in this group of income. $)^{25}$

Another stylized fact that the model reproduces is the earlier retirement of those in poor health, as shown in Figure 9. The simulations displayed in the figure above show that, until

\footnotetext{
${ }^{25}$ In another simulation we found that the retirement rate, by current labor productivity shock, is such that those with bad shocks are prone to retire in large numbers than those with positive shocks.
} 
reaching the age of 70 , the retirement profile of the unhealthy is always above that of the healthy individuals. Note also the steep jump of the retirement of the unhealthy at the age of 62. These results reproduce those in Phelan and Rust (1997). They show that individuals in bad health are roughly twice as likely to receive Social Security at 62 as at $65 .{ }^{26}$ These individuals have a higher disutility of work than those in good health. Thus, if there is market incompleteness, then the former will leave the labor force at the earliest age wherein they are entitled to receive retirement benefits.

Figure 10 displays the average consumption profile generated by the model in the benchmark case. According to evidence from Hurd (1990), among many, there is a drop in consumption at the time of retirement. Nevertheless, basic life-cycle models are not able to replicate this pattern, since consumption in these models is smooth or even growing over a lifetime. ${ }^{27}$ In order to reconcile the empirical evidence with the theory, some authors have argued that it is necessary to introduce into the basic life-cycle model the death risk (e.g., Davies (1981)) or/and an intratemporally non-separable utility (Attanasio and Weber (1993)). Our model includes these two hypotheses and, as a consequence, it is able to replicate the reduction in consumption at the time of retirement ${ }^{28}$.

\footnotetext{
${ }^{26}$ Those in good health are approximately twice as likely to receive benefits at 65 rather than 62

${ }^{27}$ The problem appears when the discount factor is larger than 1, which is possible in models with a finite horizon. In this case, the Euler equation implies that the substitution rate between consumption tomorrow and consumption today is also larger than 1. As a consequence, consumption is growing throughout the life-cycle.

${ }^{28}$ The average earning and asset life cycle profiles are similar, although the latter is smoother. They are presented in the appendix.
} 
Figure 11: Average Life-cycle Consumption

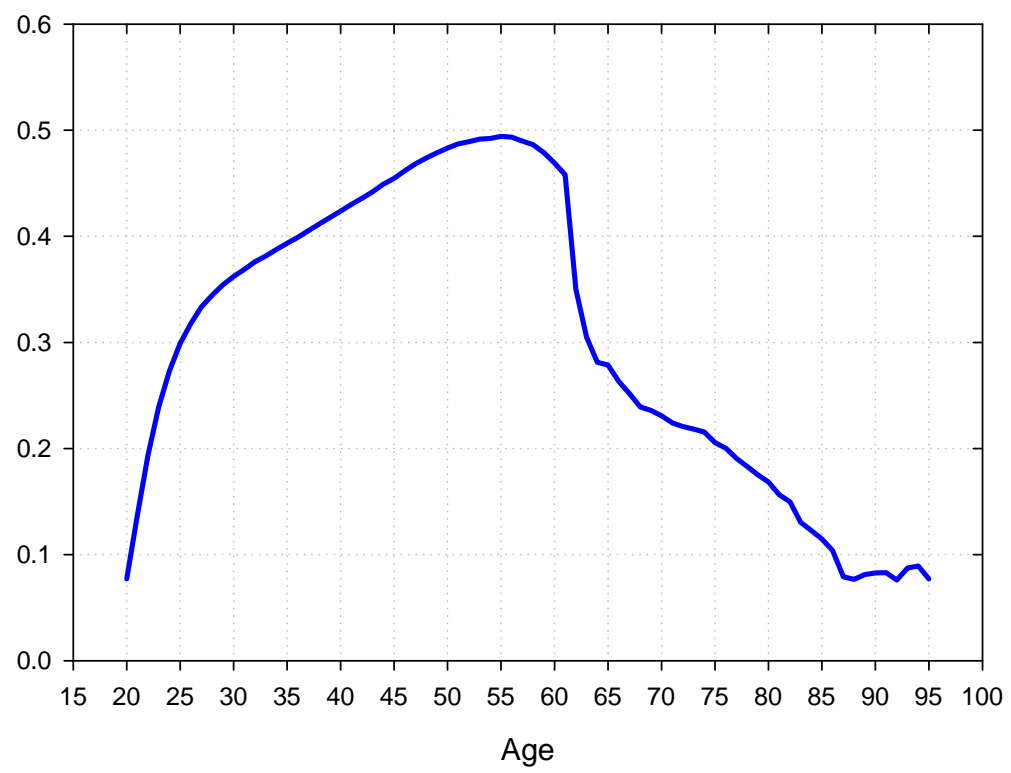

Our model is also able to reproduce very closely the peak in applications to Social Security at age 62 . We find that $55 \%$ of the total applications occur at this age, while the figure in the data is $52 \%$. Although the model also generates an increase in applications at age 65, our match is not as good as in the previous case, most probably because we do not include in the model employer-provided health insurance. As the age for eligibility for Medicare is 65 , workers postpone retirement until this age for health insurance reasons. The observed data is $18 \%$ of total application at this age and we found only $11 \%$.

\section{$5.1 \quad 1950$}

In order to investigate how well the model explains the changes in retirement between 1950 and 2000, we introduced into the model the parameters of 1950, as described in the last section. Figure 12 presents the retirement profile generated by the model and the retirement profile observed in the data. The model is also able to match the retirement behavior for individuals aged 65 - the normal age of retirement at this year - and over in 1950 .

Remember that the differences between the 1950 and 2000 economies are the changes in the experience profile, changes in the demographic composition of population, the modifications in the parameters relative to the social security system and the introduction of Medicare. As there is very little left to be explained according to Figure 12, simulation re- 
sults suggest that the changes in these variables account for almost all the observed change in retirement behavior over the period. Note also that, as it was the case in the 2000 simulation, labor force participation start declining after age 50 and the model is able to reproduce this fact, although its prediction slightly overstate this movement. In any case, the match after age 60 is very good.

Note also that the sharp decline in labor force participation at age 62 observed in 2000 is not present in the current simulation (and in the data). Hence, the model simulation shows that institutional changes related to social security are in fact effective in influence workers behavior. In this case, the introduction of early retirement (with reduced benefits) between 1950 and 2000 create a peak in the distribution of social security applications that in the latter year that was not present in the former.

Figure 12: Individuals Out of the Labor Force - 1950

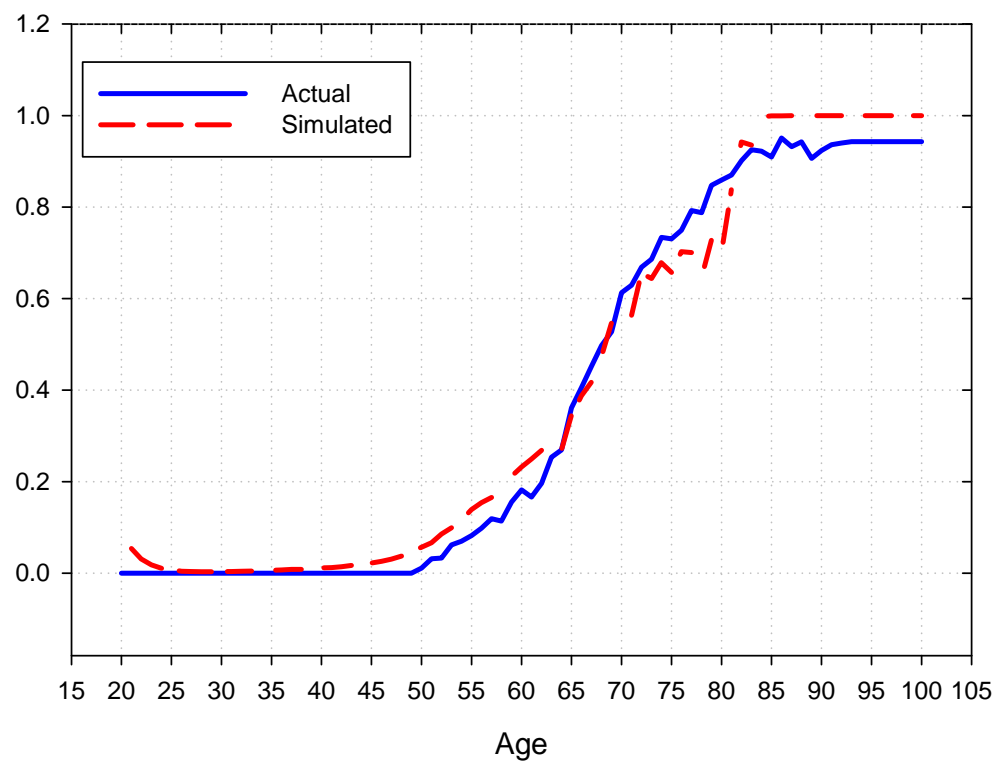

In Figure 13 we display the simulated labor profiles by age for the benchmark case and for 1950. The model is also able to reproduce another stylized fact regarding labor decision, which is the fact that older workers are working less. McGrattan and Rogerson (2004) shows that work hours of people aged 55-64 and 65-74 have fallen about $6.10 \%$ and $35.21 \%$, respectively, over the second part of the last century. In our simulations, the fraction of 
time that workers aged 55-64 spend working is 5.47\% smaller in 2000 than in 1950, while for workers aged $65-74$ that fraction decreased $35.39 \%$ in the same period.

Feldstein (1974) argues that these drops in hours worked of older people could be explained by changes in social security benefits. To investigate the effect of social security on the labor supply, we also show in Figure 13 the result of a counterfactual exercise in which we maintain constant the parameters of 2000 but those of social security, that are modified to replicate 1950 . As is apparent (see the line "changing just SS"), the changes in the social security system are very important in explaining the changes in hours worked in the period, especially for workers aged 55-64. Indeed, when we change just the parameters related to the social security system, hours worked fall by nearly $10.5 \%$, which is twice as much as the fall observed when all others variables are changed. Besides more generous benefits, this sizeable impact is also explained by the reduction of minimum retirement age for social security benefits (from 65 in 1950 to 62 in 2000). In the case of workers aged 65-74, the model suggests that social security accounted for about $60 \%$ of the fall in hours worked in the period. ${ }^{29}$

Figure 13: Average Hours Worked

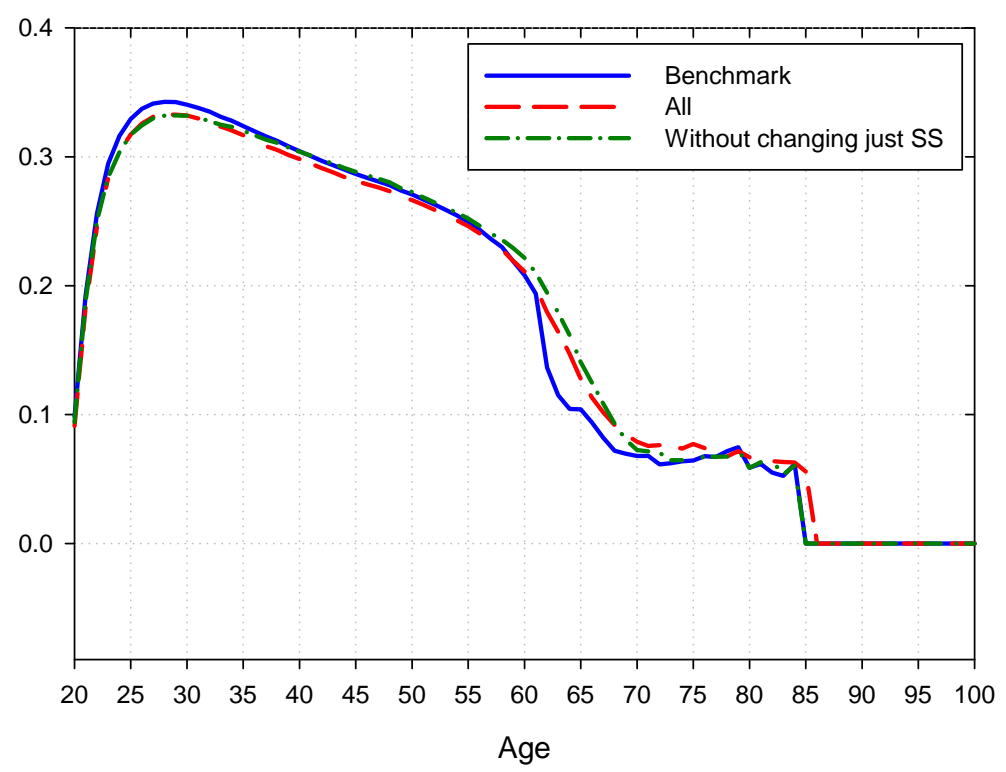

\footnotetext{
${ }^{29}$ The econometric evidence on the effect of social security on labor supply is inconclusive. For example, Hurd and Boskin (1984), Burtless (1986) have found negative relationship, while Krueger and Pischke (1992) have found no effect of social security on labor supply.
} 
Table 6 presents some descriptive statistics obtained from the two steady states.

Table 6: Descriptive Statistics

\begin{tabular}{lcc}
\hline \hline & 2000 & 1950 \\
\cline { 2 - 3 } Capital-Output Ratio & 3.01 & 3.25 \\
Gross Interest Rate & $6.54 \%$ & $5.52 \%$ \\
Average Hours worked & 0.286 & 0.275 \\
Consumption tax & $8.4 \%$ & $13.08 \%$ \\
Gini Index - Earnings & 0.4037 & 0.4203 \\
Gini Index - Wealth & 0.8401 & 0.8676 \\
Gini Index - Consumption & 0.3502 & 0.3542 \\
\hline
\end{tabular}

In both years the match is very good and close to the observed data. For instance, capital-output ratio in general is found to be around three, and in both cases we are close to this figure. Likewise, hours worked in RBC models are target to one-third, but in OLG model it should be smaller and in line with our values.

\subsection{Unraveling the channels to the changes in retirement}

In this sub-section we investigate the role and measure the relative importance of the changes in the social security system, and in demography to the changes in the retirement pattern. In the next subsection we study the impact of positive wealth shocks.

In Figure 14 we modify the benchmark case changing the rules of Social Security to those of 1950, keeping everything else constant. In Figure 15, Medicare was eliminated, again keeping all other parameters as in the benchmark case. 
Figure 14: Individuals Out of the Labor Force

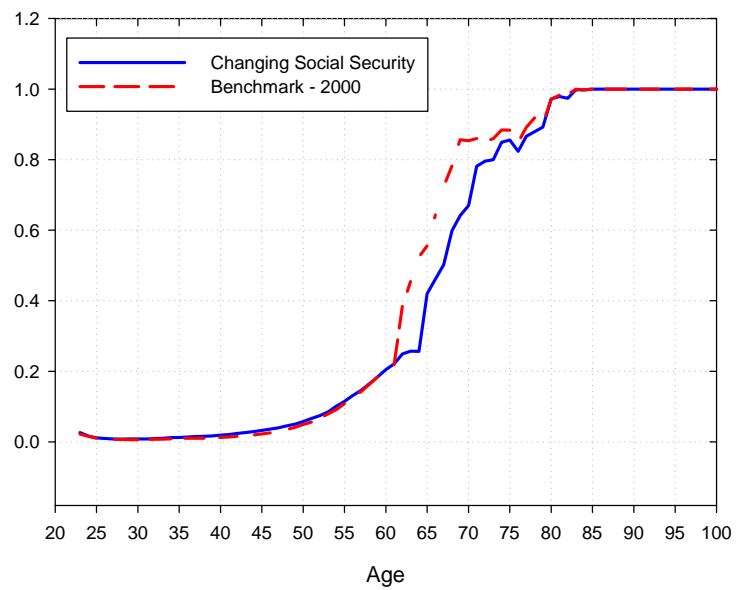

Figure 15: Individuals Out of the Labor Force

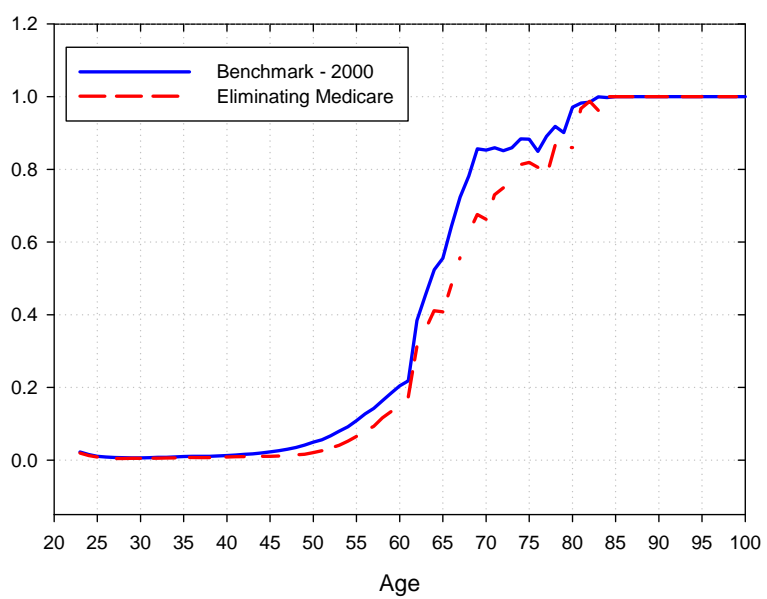

In both cases the impact on retirement is sizable. For instance, the retirement rate of 65 years old individuals is a bit above $60 \%$ in the baseline economy. This rate declines to $40 \%$ once we change social security parameters, and to $42 \%$ if Medicare insurance did not exist. For 70 year old individuals, the decline is from $85 \%$ to $66 \%$ and $68 \%$, respectively. In the latter case, for instance, without the incentive of a public health insurance at 65, individuals tend to stay longer in the work force. Among other things, because they need the income (and savings) to pay for medical expenses.

In Figure 16 below we modify the demographic profile of the benchmark case for that of 1950. The result is that the lower life expectancy of 1950 would make older workers in 2000 to leave earlier the labor force. Or, what is the same, longer life expectancy causes a postponement of retirement in the model. This happens because once the survival probabilities are shifted up, there are also an increase in the intertemporal discount rate, leading agents to save more and work harder. Hence, the observed increase in longevity in the second half of the previous century does not help to explain the increase in retirement. Much the opposite, it has negative impact that, apparently, was compensated by the changes in Medicare and Social Security. The result of Kalemli-Ozcan and Weil (2006) that the fall in mortality (or reduction of mortality risk) increases retirement because individuals would better plan and save more does not hold in our richer environment. In contrast, our simulation partly favors Bloom et al. (2007) as they show that, depending on social security provisions, improvement in life expectancy may increase working life. 
Figure 16: Individuals Out of the Labor Force

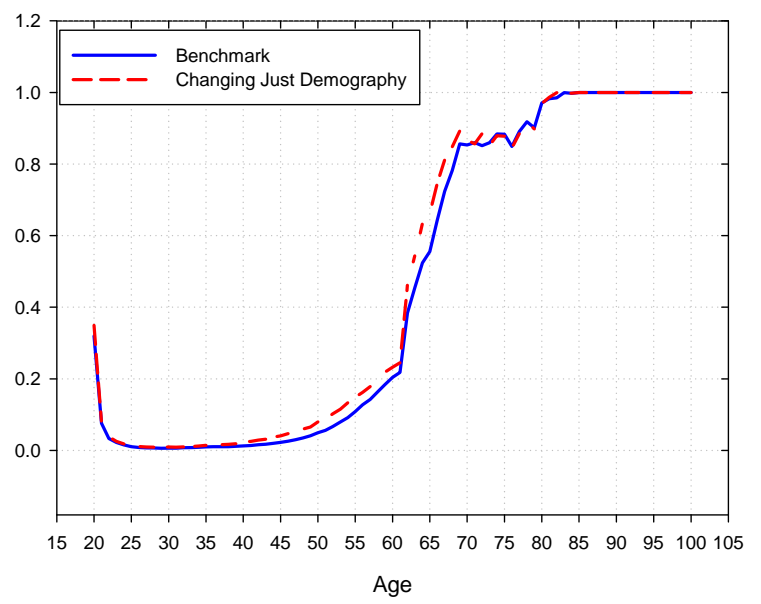

Figure 17: Individuals Out of the Labor Force

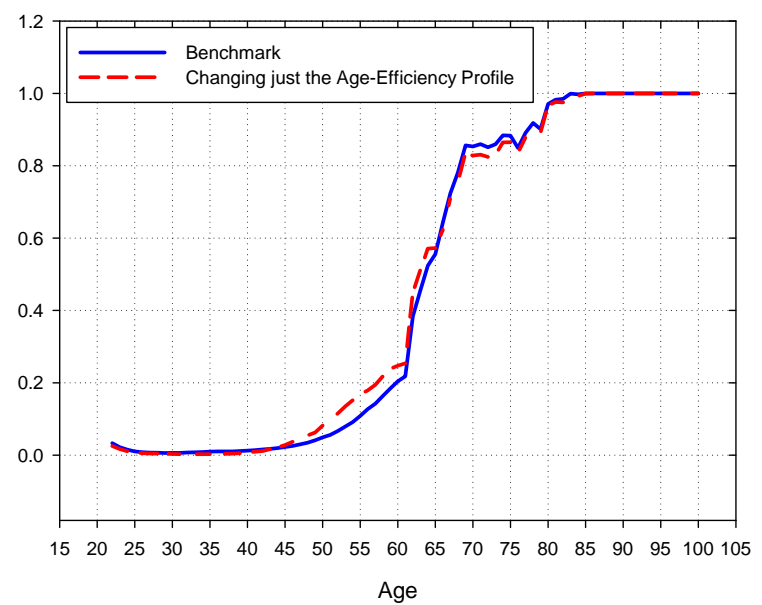

In the simulation presented in Figure 17 the age-efficiency profile in the benchmark economy is substituted by that of 1950 . The impact in this case is not too large, and for ages below 65 goes in the wrong direction. After this age the impact is positive but small. This contrasts with Ferreira and Pessôa that found that this channel was a key force for the increase in retirement. Possible explanations for the different results are the fact that we use Census data and their calibration is base on CPS data and the many channels we introduce in our model.

Table7 presents in a different form some of the numbers of the simulations above for ages 62 to 69 . The second column presents the 2000 simulation ("Benchmark") and the last column the 1950 simulation, where all factors were changed at the same time. The remaining columns display the isolated impact (i.e., keeping all other factors constant) of Social Security, Demography, Age-Efficiency and Medicare, respectively, on retirement rate. The closer the number in one of these columns is from the 1950 value, the stronger the effect of the corresponding factor. 
Table 7: Decomposition of the changes in Retirement

\begin{tabular}{ccccccc}
\hline \hline Age & \multicolumn{5}{c}{ Variable Changed } \\
\hline & Benchmark & Social Security & Demography & Age-Efficiency & Medicare & All (1950) \\
62 & 38.4 & 24.9 & 46.1 & 44.9 & 31.1 & 26.8 \\
63 & 45.4 & 25.7 & 54.3 & 51.0 & 36.0 & 27.3 \\
64 & 52.3 & 25.8 & 63.2 & 56.1 & 40.1 & 26.9 \\
65 & 56.5 & 43.0 & 66.2 & 57.2 & 41.1 & 34.5 \\
66 & 63.3 & 46.2 & 74.6 & 61.2 & 48.2 & 38.7 \\
67 & 72.3 & 50.2 & 81.1 & 70.8 & 55.7 & 41.7 \\
68 & 77.1 & 59.9 & 84.7 & 75.4 & 62.5 & 47.3 \\
69 & 85.6 & 64.2 & 89.2 & 83.5 & 67.6 & 54.6 \\
\hline
\end{tabular}

For all ages but 65 changes in Social Security have the stronger impact on retirement. For instance, the estimated retirement rate at age 62 when changing only the rules of Social Security is $24.9 \%$, very close to the value of the full 1950 simulation $^{30}$. $(26.8 \%)$ and smaller than that of all the other three cases. At age 65 the impact of Medicare is slightly stronger than Social Security changes ( $41 \%$ and $43 \%$, respectively). In all other years, the isolated impact of Medicare is the second stronger. At age 66, for instance, only by eliminating Medicare from the simulated benchmark the model estimate a retirement rate, 48.\%, only ten points above that of the 1950 .

As remarked above, changes in age-efficiency profile between the two years had a very small impact. At age 69, its isolated impact is only a reduction of two years of the retirement rate with respect to the full 2000 simulation, more or less the same figure for ages 66 to 68 . For ages 62 to 65 its impact goes in the opposite direction, the same result for chances in the demographic profile for every age. In both cases retirement rates in 2000 would be higher with the corresponding 1950 parameters.

\footnotetext{
${ }^{30}$ Another way to see this result is: if in 2000 the rules of Social Security were the same as in 1950, retirement rate at age 62 would be almost the same as in 1950
} 


\subsection{Wealth effects}

Retirees in 2000 lived the last ten years of their working life in a period of strong run-up in stock market. In this period stock prices (measured by the S \&P 500) appreciated at an average rate twice as large as in the previous decades. Life-cycle theory predicts that in response to wealth shocks such as this people will raise their consumption of goods and services as well as leisure. Most empirical studies focus on measuring the effect of unexpected increase in wealth on consumption and ignore the impact on leisure. One exception is Coronado and Perozek (2003). They find larger health effects on retirement for the cohort that experience the bull market of the nineties. In particular, they estimate that those in their sample that held corporate equity prior to the stock market boom retired seven months earlier than those who did not.

It would be interesting to check if our model is able to capture this type of wealth effect. If so, it would help us to understand further the differences in retirement behavior between the two periods of study. This is so because the appreciation of stock market in the forties (measured by the Dow Jones) was less than 3\% a year (and in 1950 it was still $40 \%$ below the peak of 1929) and the number of individuals owning stock in 1950 was very small.

Note, however, that Coronado and Perozek (2003) estimated a reduced form model. In our general equilibrium framework it is very hard to model capital gains. We chose the following strategy. We used interest rate as a proxy for the return on equity. Starting at age 55 , individuals are subject to idiosyncratic shocks to the return of their assets, so that now the relevant interest rate after this age is given by

$$
\widetilde{r_{t}}=r_{t}+\xi_{t}, \quad \xi_{t}^{\sim} N\left(0, \sigma^{2}\right)
$$

The first component in the right hand side is determined as before. The second is an i.i.d shock $^{31}$. Hence, older individuals do not know with certainty what will be the return of their assets in the next period. The model was simulated with this simple stochastic process of asset return, keeping everything else as before. Individuals were then separated in groups, according to the average value of realized shocks in a given age. The picture below presents the retirement profile of the top quintile of the distribution ${ }^{32}$, the bottom quintile and the

\footnotetext{
${ }^{31}$ We set $\sigma^{2}$ to 0.001 .

${ }^{32} \mathrm{An}$ agent in this group is such that the value of interest shocks at a given age (e.g., 55) is among the twenty per cent higher in the sample at this age. This same individual - if still in the labor force - may be
} 
average profile.

Figure 18: Retirement by Interest Rate Shocks

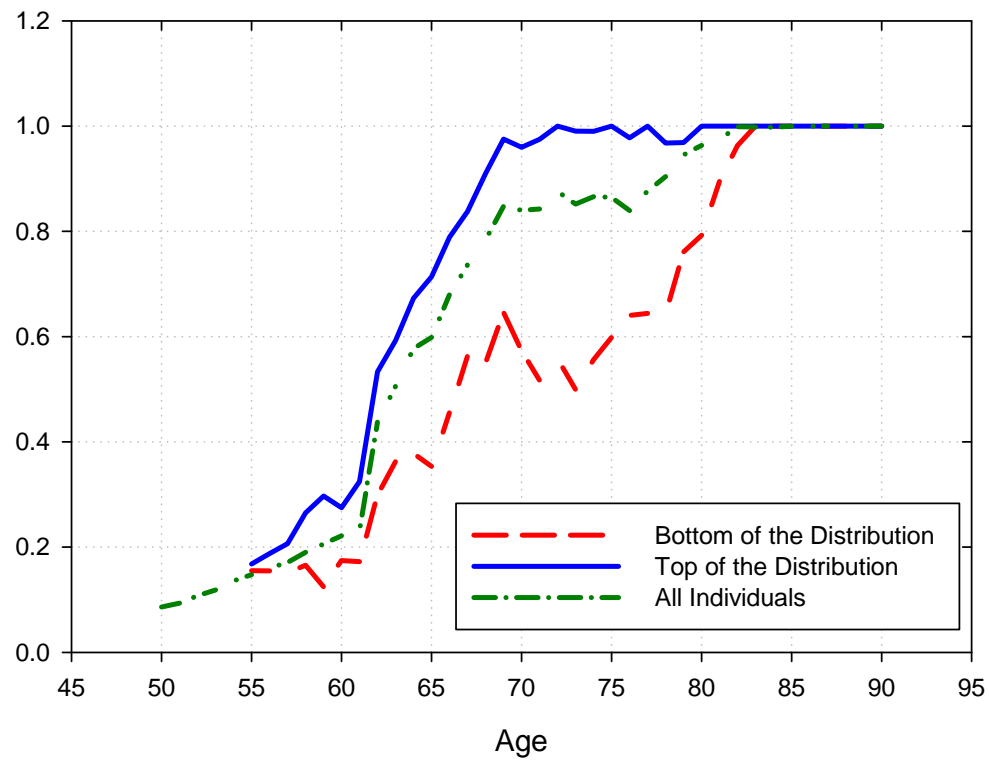

People in the top of distribution are those whose realized asset return was higher for a given age, after the age 55. The retirement rate in this case is always above that of the bottom quintile - people with poor realizations of returns - and that of the average individual $^{33}$. Hence, workers with the largest unexpected gain in their assets leave earlier the labor force. Similarly as estimated by Coronado and Peronovek (2003) in a partial equilibrium econometric model, we found that at least part of an unpredicted increase in wealth is used to finance an increase in leisure in the form of earlier retirement. Therefore, this result is an indication that the markedly different behavior of financial markets in the years prior to 1950 or 2000 may have influenced the decision to retirement of workers in these two years.

in a different group.in any other age (e.g., 56), depending on his shock.

${ }^{33}$ By construction, the latter coincides with the profile of the model without return shocks. 


\subsection{Retirement Earnings Test and Delayed Retirement Credit}

Under the retirement earnings test, Social Security benefits are reduced if earnings exceed specified amounts. However, the Senior Citizens Freedom to Work Act of 2000 abolished the Social Security earnings test for those between the full retirement age and 70 years of age. The removal of the RET allows older workers to remain in the labor force beyond their FRA without having their retirement benefits withheld. We use our model economy to investigate the effect of this policy change on retirement. In particular,we run a counter-factual experiment in which the retirement earnings test for individuals age 65-70 is eliminated, keeping everything else as its benchmark calibration. Given that the elimination of RET is likely to have higher impact on higher earners than on lower ones, Figure 20 shows the share of retirees for ages 55-75 for the first and fifth quintile of the average past earnings distribution. As one can see in Figure 19, retirement falls mostly among higher income individuals. Indeed, the share of retirees aged 65, 66 and 67 without RET is, respectively, 4.55\%, 7.4\% and $4.7 \%$ higher in comparison to the benchmark case for the fifth quintile, against $0.4 \%$, $0.6 \%$ and $0.3 \%$ obtained among the first quintile.

Figure 19: Individuals Out of the Labor Force by Average Past Earnings

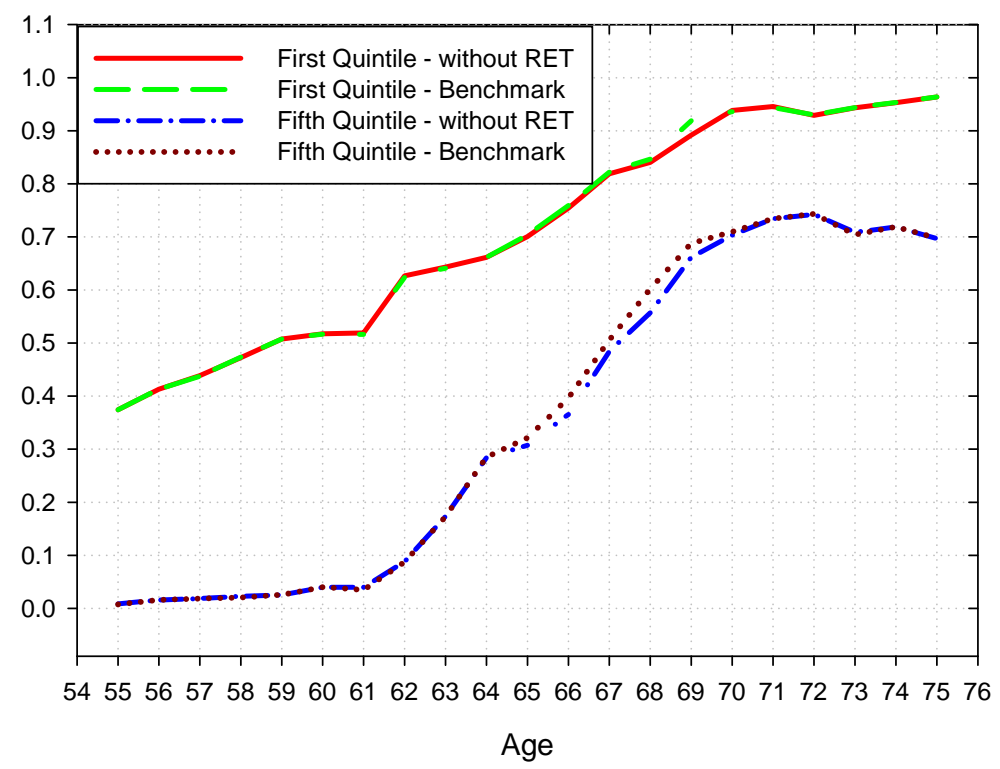

Now we investigate the isolated impact of Social Security's Delayed Retirement Credit on retirement of older men. The credit constitutes another type of incentive built into the 
program in order to promote work at older ages. It raises lifetime social security benefit payments for recipients who delay receiving benefits after age 65. We use our model to investigate the impact of the DRC on the retirement behavior. Figure 20 shows the distribution by age of applications for social security produced by the model in two cases: the full simulation using 2000 parameters and another using 2000 parameters but leaving the delayed retirement credit unchanged, that is, $g_{d}=0 .{ }^{34}$ The increase in the delayed retirement credit reduces the peak in retirement at age 65 , but does not affect at all behavior at age 62 . The model estimates that $15 \%$ of the applications would occur at age 65 with $g_{d}=0$ as opposed to less than $10 \%$ with the new rules. ${ }^{35}$

Figure 20: Individuals Out of the Labor Force

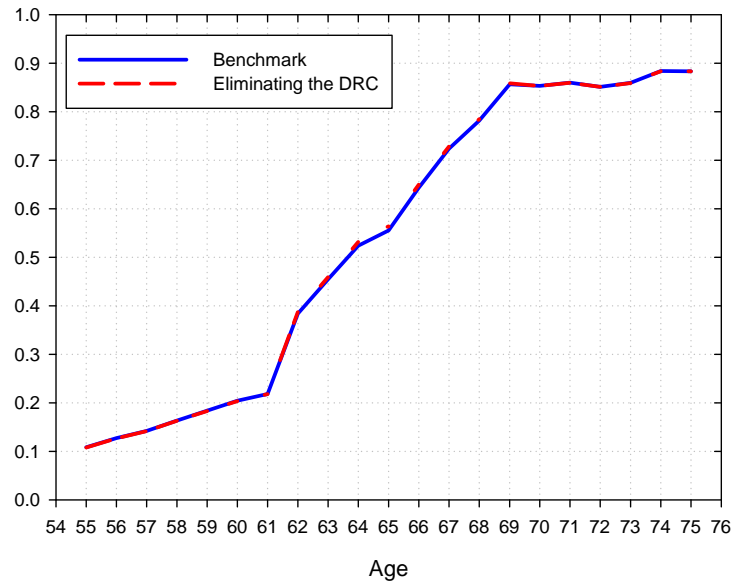

Figure 21: Distribution of Applications for Social Security Benefits

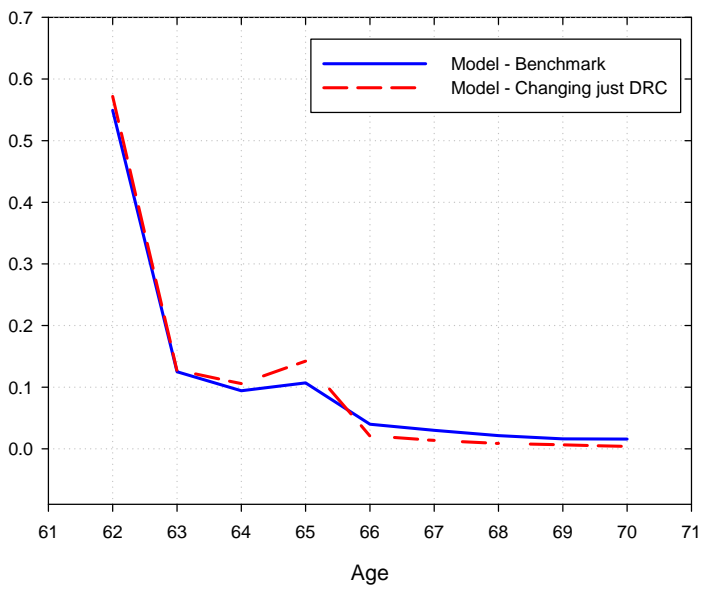

\subsection{Fiscal effects}

Table 8 displays further results on the effects of the changes in social security legislation, demography and productivity profile upon the aggregate retirement behavior and on the benefits paid-output ratio. The first column shows which factor was modified in the simulation. The second shows the aggregate retirement rate - the ratio between retired population and total population - and the third column the total benefits paid-output ratio - social

\footnotetext{
${ }^{34}$ Notice that, for simplicity, we have not taken into account the retirement earning test. Moreover, Gruber and Orszag (2003) show that the retirement earning test exerts no robust influence on the labor supply decisions of men.

${ }^{35}$ The former result is close to that observed in a sample of individuals in good health conditions used by Rust and Phelan (1997).
} 
security spending as a share of GDP. Finally, the fourth column presents the sensibility of the total benefits paid-output ratio to the variations in the retirement rate.

One can see from Table 8, when just the parameters of the social security are modified, aggregate retirement rate goes down by $15.61 \%$ (i.e., from 15.82 to 13.35.), while the elimination of Medicare entails an even bigger fall (from $15.82 \%$ to $12.99 \%$ ). In contrast, introducing into the model just the 1950 life-expectancy profile, we obtain an increase of $12.64 \%$ in retirement (it goes to $17.82 \%$ of total labor force), whereas changing just the age-efficiency profile yields an small increase of $1.51 \%$. Thus, changes in social security and medicare were the most important source of increases in aggregate retirement rate, while changes in demography and in the age-efficiency profile have contributed to raise labor force participation, although the latter only marginally.

Table 8 also shows that the increases in retirement caused by changes in the social security have much larger effects on the total benefits paid-output ratio than those caused by the other factors. In fact, one percentage point decrease in retirement is associated with an fall of 0.93 percentage point in the benefits paid-output ratio. This variation rate is significantly smaller for the case in which we eliminate Medicare, 0.014, and it is negative for changes in demography, -0.015, and in the age-efficiency profile, -0.083.

Table 8: Changes in Aggregate Retirement and Social Security Expenses

\begin{tabular}{lccc}
\hline \hline \multicolumn{1}{c}{ Variable } & Retirement rate $=\lambda \%$ & Total Benefits $/$ Output $=b \%$ & $\Delta b / \Delta \lambda$ \\
\hline Benchmark (2000) & 15.82 & 3.41 & - \\
Social Security & 13.35 & 1.11 & 0.930 \\
Demography & 17.82 & 3.38 & -0.015 \\
Medicare & 12.99 & 3.45 & 0.014 \\
Age-efficiency profile & 16.06 & 3.39 & -0.083 \\
All & 12.11 & 1.13 & 0.614 \\
\hline
\end{tabular}

The previous findings allow one to conclude that if social security had not been changed, retirement could still be much higher in 2000 than 1950, but social security expenses as a share of output would be much smaller than otherwise. From a policy perspective, these results imply, for example, that the impact of the aging population on the sustainability of the social security system on the long-run may be lower (or even has the opposite effect as 
our findings suggest) than one could think. The model shows that, everything else constant, longevity encourages longevity encourages workers to stay longer in the workforce.

In contrast, the increase of retirement benefits has very large effects on social security expenses as a share of output. This is so because as social security payments become more generous, savings and hours worked and thereby the output per capita fall, because agents do not need now to save for the retirement as much as they did before. Hence, increases in social security benefits not only raise the number of retirees, but also undermine the revenue base of the system.

\section{Conclusions}

In this paper we have studied a stochastic life-cycle economy in which individuals pick optimally the time to leave the labor force. The model mimics relevant features of the American economy and takes special care in the calibration of the social security system. Simulations were able to match very closely the changes in retirement of American men from 1950 to 2000 as well as the modification of the labor profile of the elderly. The model was able to reproduce differences in the retirement profile of the rich and the poor and also of the healthy and unhealthy. The match of the peak of the distribution of social security applications at age 62 was particularly good.

The model suggests that the changes in social security over the second part of the last century and the introduction of Medicare account for most of the changes in the retirement profile by age. In contrast, we found that the isolated effect of demographic factor would be to postpone the date workers leave the labor force. Hence, the increase in longevity observed in the last century cannot explain the reduction of the labor force participation of the elderly. The impact of the technology factors represented in the change in age-efficiency profile was mixed and small at best. The contrast with Ferreira and Pessôa (2007) may be due to the different data bases used or to the fact that the current model includes many other factors affecting retirement. A contrafactual exercise found that wealth shocks such as that experienced by equity holder in the nineties can potentially explain part of the observed increase in retirement.

Changes in Social Security and Medicare are the most important source of changes in aggregate retirement rate. The former is also the key factor behind the sizeable increase in 
the social security expenses as share of output, even more important than population aging that usually receives way more attention.

A further evidence of the importance of social security legislation to the labor decision of the old is the finding that the increase in the delayed retirement credit, as it raises the incentives to continue working after age 65, has played an important role in preventing workers from retiring and thereby in reducing the peak of retirement at this age.

\section{References}

[1] Atkinson, A.B., 1991. The Distribution of Wealth and The Individual Life Cycle. Oxford Economic Papers: No. 23, pp. 239-254.

[2] Attanasio, O. and Weber, G., 1993. Consumption Growth, the Interest Rate and Aggregation. Review of Economic Studies, 60(3), pp. 631-649.

[3] Auerbach, A. and Kotlikoff, L., 1987. Dynamic Fiscal Policy, Cambridge University Press.

[4] Bell, F. and Miller, M., 2005. Life Tables for The United States Social Security Area 1900-2100. Social Security Administration: Actuarial Study No. 120.

[5] Blondal, S. and Scarpetta, S., 1998. The Retirement Decision in OECD Countries. OECD Economics Department WP 202.

[6] Bloom, D.,Canning, D., Mansfield R. and Moore, M., 2007, "Demographic Change, Social Security Systems, and Savings," Journal of Monetary Economics 54: 92-114.

[7] Burtless, G., 1986. Social Security, Unanticipated Benefit Increases and the Timing of Retirement. Review of Economic Studies, 53(5), pp. 781-805.

[8] Coile, C. and Gruber, J., 2007. Future Social Security Entitlements and the Retirement Decision. The Review of Economics and Statistics, 89(2), pp. 234-246.

[9] Conde-Ruiz, J. and V. Galasso, 2003, Early Retirement, Review of Economic Dynamics, 6(1), pp. 12-36. 
[10] Davies, J., 1981. Uncertain Lifetime, Consumption and Dissaving in Retirement. Journal of Political Economy, 89(31), pp. 561-77.

[11] Diamond, P. and Hausman, J., 1984. Retirement and Unemployment Behavior of Older Men. In Retirement and Economic Behavior, H. Aaron and G. Burtless, eds., Washington:Brookings Institution.

[12] Diaz-Gimenez, J. and J. Diaz-Savavedra, 2009, Delaying Retirement in Spain, Review of Economic Dynamics, 12(1), pp. 147-167.

[13] Dwyer and O. Mitchell, 1999, "Health problems as determinants of retirement: are self-rated measures endogenous? Journal of Health Economics. pp. 173-93.

[14] Domeij, D. and Flodén, 2006, The labor-supply elasticity and borrowing constraints: Why estimates are biased, Review of Economic Dynamics, vol. 9(2), pp. 242-262.

[15] Eisensee, T., 2006, Fiscal Policy and Retirement in the Twentieth Century, manuscript, Institute for International Economic Studies, Stockholm University.

[16] Feldstein, M., 1974. Social Security, Induced Retirement, and Aggregate Capital Accumulation. Journal of Political Economy, 82(5), pp. 905-26.

[17] Ferreira, P. C. and Pessôa, S. A., 2007. The Effects of Longevity and Distortions on Education and Retirement. Review of Economic Dynamic, 10(3), pp. 472-493.

[18] Finkelstein, A. and McKnight, R., 2008. What did Medicare do? The initial impact of Medicare on mortality and out of pocket medical spending. Journal of Public Economics, vol. 92(7), pages 1644-1668.

[19] Floden, M. and Lindé, J., 2001. Idiosyncratic Risk in the United States and Sweden: Is There a Role for Government Insure?. Review of Economic Dynamics, 4(2), pp 406-437.

[20] French, E., 2005, "The Effects of Health, Wealth, and Wages on Labour Suppy and Retirement Behaviour," Review of Economics Studies (2005) 72, pp. 395-427.

[21] French, E., and Jones, J.B., 2004. On the Distribution and Dynamics of Health Care Costs. Journal of Applied Econometrics, 19(4), 705-721. 
[22] French, E., and Jones, J.B., 2007. The Effects of Health Insurance and Self-Insurance on Retirement Behavior. Federal Reserve Bank of Chicago, Working Paper 2001-19.

[23] Graebner, W., 1980. A History of Retirement: The Meaning and Function of an American Institution. 1885-1978, New Haven, CO: Yale University Press.

[24] Gruber, J. and Wise, D., 1999. Social Security Programs and Retirement around the World. The University of Chicago, Chicago.

[25] Gruber, J. and Orszag, P., 2003. Does the Social Security Earnings Test Affect Labor Supply and Benefits Receipt?. National Tax Journal, 56(4), pp. 755-773.

[26] Gustman, T. and Steinmeier, T. L., 1986. A Structural Retirement Model. Econometrica, $54(3), 555-584$.

[27] Heckman, J., Lochner, L. and Todd, P., 2003. Fifty Years of Mincer Earnings Regressions. NBER Working Papers $\mathrm{n}^{\circ} 9732$.

[28] Huggett, M., 1996. Wealth Distribution in Life-Cycle Economies. Journal of Monetary Economics, 38(3), pp. 469-494.

[29] Huggett, M. and Ventura, G., 1999. On the Distributional Effects of Social Security Reform. Review of Economic Dynamics, 2(3), 498-531.

[30] Huggett, M. and Parra, J. C., (2010). How Well Does The US Social Security System Provide Social Insurance?. Journal of Political Economy. Vol. 118(1).

[31] Hubbard, R., J. Skinner, and S. Zeldes., 1994. The Importance of Precautionary Motives in Explaining Individual and Aggregate Saving. Carnegie-Rochester Series on Public Policy, 40, 59-125.

[32] Hubbard, R., J. Skinner, and S. Zeldes., 1995. Precautionary Saving and Social Insurance. Journal of Political Economy, 103(2), pp. 360-399.

[33] Hurd, M., 1990. Research on the Elderly: Economic Status, Retirement, and Consumption and Saving. Journal of Economic Literature, 28(2), pp. 565-637.

[34] Hurd, M. and Boskin, M. J., 1984. The Effect of Social Security on Retirement in the Early 1970s. Quarterly Journal of Economics, 99(4), pp. 767-790. 
[35] Imrohoroglu, A., Imrohoroglu, S. and Jones, D., 1995. A Life Cycle Analysis of Social Security. Economic Theory, 6(1), pp. 83-114.

[36] Juster, F. T. and Stafford, F. P., 1991. The Allocation of Time: Empirical Findings, Behavioral Models and Problems of Measurement. Journal of Economic Literature, 29(2), pp. $471-522$.

[37] Kalemli-Ozcan, S. and Weil, D. N., 2006. Mortality Change, the Uncertainty Effect and Retirement. Meeting Papers 28, Society for Economic Dynamics.

[38] Kaplan, G., 2007. Inequality and the Lifecycle, Manuscript, NYU

[39] Kopechy, K . A., 2006. The Trend in Retirement. Meeting Papers 187, Society for Economic Dynamics.

[40] Kotlikoff, L., 1989, Health Expenditures and Precautionary Savings." In What Determines Savings? by L. Kotlikoff. Cambridge, Mass.: MIT Press.

[41] Krueger, A. and Pischke, J., 1992. The Effect of Social Security on Labor Supply: A Cohort Analysis of the Notch Generation. Journal of Labor Economics, 10(4), pp. 412437.

[42] McGarry, K., 2004. Health and Retirement: do Changes in Health Affect Retirement expectations? Journal of Human Resources, 39(3). pp. 624-648

[43] McGrattan, E. R. and Rogerson, R., 1998. Changes in Hours Worked Since 1950. Federal Reserve Bank of Minneapolis Quarterly Review, 22(1): 2-19.

[44] Meara, E., White, C. and Cutler, D. M., 2004. Trends In Medical Spending By Age, 1963-2000. Health Affairs, 23 (4), pp. 176-183.

[45] Moffitt, R.A., 1987. Life-Cycle Labor Supply and Social Security: A Time-Series Analysis. In G. Burtless (ed.) Work, Health, and Income among the Elderly. The Brookings Institution, Washington, D.C.

[46] Nishiyama, N. and Smetters, K., 2007. "Does Social Security Privatization Produce Efficiency Gains?," The Quarterly Journal of Economics, 122(4), pp. 1677-1719, November. 
[47] Parsons, D., 1982. The Male Labour Force Participation Decision: Health, Reported Health, and Economic Incentives. Economica, 49(193), pp. 81-91.

[48] Ríos-Rull, J. V., 1996. Life-Cycle Economies and Aggregate Fluctuations. Review of Economic Studies, 63(3): 465-489.

[49] Rojas, J. and C. Urrutia, 2008, Social Security Reform with Uninsurable Income Risk and Endogenous Borrowing Constraits. Review of Economic Dynamics, 11, pp. 83-103.

[50] Ruhm, C. J., 1990. Bridge Jobs and Partial Retirement. Journal of Labor Economics, $8(4), 482-501$.

[51] Rust, J. and Phelan, C., 1997. How Social Security and Medicare Affect Retirement Behavior in a World of Incomplete Markets. Econometrica, 65(4), pp. 781-831.

[52] Sala-i-Martin, X., 1998. A Positive Theory of Social Security. Journal of Economic Growth, 1(2), pp. 277-304.

[53] Stock, J. and Wise, D., 1990. Pensions, the Option Value of Work, and Retirement. Econometrica, 58(5), pp. 1151-1180.

[54] Storesletten K, Telmer CI, Yaron A., 2004. Consumption and Risk Sharing Over the Lifecycle. Journal of Monetary Economics 51: 609-633.

[55] Sueyoshi, G. T., 1989. Social Security and the Determinants of Full and Partial Retirement: A Competing Risks Analysis. NBER Working Paper \#3113. 